NASA Technical Memorandum 100123

AIAA-87-1951

\title{
Low Power Arcjet Thruster Pulse Ignition
}

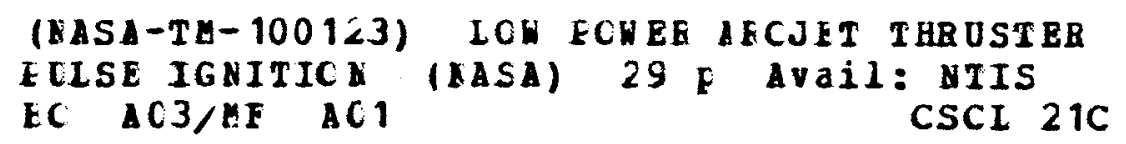

Charles J. Sarmiento and Robert P. Gruber Lewis Research Center

Cleveland, Ohio

Prepared for the

23rd Joint Propulsion Conference cosponsored by the AIAA, SAE, ASME, and ASEE San Diego, California, June 29-July 2, 1987

\section{Nusn}




\section{ERRATA}

NASA Technical Memorandum 100123

(AIAA-87-1951)

\section{LOW POWER ARCJET THRUSTER PULSE IGNITION \\ Charles J. Sarmiento and Robert P. Gruber September 1987}

\footnotetext{
Page 6, paragraph 2: The sentence should read, The current transformers used to measure short duration current transients had scale factors of $0.1 \mathrm{~V} / \mathrm{A}$ and $1.0 \mathrm{~V} / \mathrm{A}$ and bandwidths of $120 \mathrm{~Hz}$ to $20 \mathrm{MHz}$ and $140 \mathrm{~Hz}$ to $35 \mathrm{MHz}$, respectively.

Page 14: Date for reference 9 should be June 1986. References 13 and 14 should be interchanged.

Page 21: Current scale factor should be 2 A/DIV.
} 
LOW POWER ARCJET THRUSTER PULSE IGNITION

Charles J. Sarmiento and Robert P. Gruber

National Aeronautics and Space Administration

Lewis Research Center

Cleveland, Ohio 44135

\section{SUMMARY}

An investigation of the pulse ignition characteristics of a $1 \mathrm{~kW}$ class arcjet using an inductive energy storage pulse generator integral with a pulse width modulated power converter identified several thruster and pulse generator parameters that influence breakdown voltage including pulse generator rate of voltage rise. This work was conducted with an arcjet tested on hydrogennitrogen gas mixtures to simulate fully decomposed hydrazine. Over all ranges of thruster and pulser parameters investigated, the mean breakdown voltages varied from 1.4 to $2.7 \mathrm{kV}$. Ignition tests at elevated thruster temperatures under certain conditions revealed occasional breakdowns to thruster voltages higher than the power converter output voltage. These postbreakdown discharges sometimes failed to transition to the lower voltage arc discharge mode and the thruster would not ignite. Under the same conditions, a transition to the arc mode would occur for a subsequent pulse and the thruster would ignite. An automated 11600 cycle starting and transition to steady state test demonstrated ignition on the first pulse and required application of a second pulse only two times to initiate breakdown. Furthermore, no thruster damage or erosion was observed following the 11600 starts and transitions to steady state operation.

\section{INTRODUCTION}

Demands for increased specific impulse propulsion on modern communications satellites have led to reevaluation of the role of arcjets. The data base accumulated at the 1 and $2 \mathrm{~kW}$ power levels through government-sponsored programs in the late 1950 's and early $1960^{\prime}$ 's centered mainly on operation with hydrogen (ref. 1). Efforts to operate a first-generation $1 \mathrm{~kW}$ arcjet on propellants other than hydrogen met with little success (ref. 1). Current research indicates that specific impulse levels well above $400 \mathrm{sec}$ are attainable with hydrazine (ref. 2). This makes the arcjet a very attractive candidate to succeed resistojet and low-thrust chemical propulsion, currently in use for geosynchronous stationkeeping of communications satelites. This succession, however, is dependent on the resolution of issues concerning the practical application of the arcjet. A typical station keeping mission will involve hundreds of starting cycles. Development of a reliable starting procedure is, therefore, critical to the application of this thruster.

Many procedures have been used to ignite arcjet thrusters. In one common technique (ref. 3), the discharge was initiated with a moderate open circuit voltage in an easily ionized gas such as argon or neon. The propellant of choice was then blended in and the starting gas flow reduced, until full transition to steady state operation with the desired propellant was achieved.

This paper is declared a work of the U.S. Government and is nol subject in copyright prolection in the Unlied Stales. 
This approach decreases the high voltage required for breakdown and is a convenient laboratory technique. The complication of managing an additional propellant for arc ignition, however, presents obvious problems for satellite application.

A drawn arc concept was used in the $1 \mathrm{~kW}$ arcjet designed by the Plasmadyne Corp (ref. 4). In this technique the current is initiated with the electrodes in contact, and then the electrodes are mechanically separated as propellant flow is established (ref. 4). This method simplifies electrical requirements but complicates the mechanical design of the arcjet. In addition, as cathode and anode erosion will certainly affect electrode contact, the reliability of this method cannot be guaranteed.

In a third, often used, method the open circuit voltage was simply set at a high enough level to cause Paschen breakdown of the propellant. This technique was used to start a $2 \mathrm{~kW}$ Plasmadyne thruster which was life tested using hydrogen for $150 \mathrm{hr}$ in 1963 (ref. 5). At full propellant flow this method requires a power supply capable of thousands of volts and increases the weight and complexity of the system.

In a more recent test (ref. 6) of a modified version of the $1 \mathrm{~kW}$ Plasmadyne thruster the high voltage requirement was reduced by lowering the propellant flow rate, and consequently the interelectrode pressure. In that test, large current and voltage transients accompanied startup, and transition to a steady state occurred slowly, causing significant damage to the anode.

Since that test, the $1 \mathrm{~kW}$ class arcjet and its associated power supply have undergone significant development (refs. 7 and 8 ). The power supply design includes both a starting circuit that provides brief high voltage pulses to initiate the discharge and a main output circuit for rapid current regulation during steady state operation (ref. 9). The thruster incorporates strong vortex flow stabilization to force the arc quickly into a steady state condi. tion. Arcjet starting characteristics have been studied in detail (refs. 10 and 11). Efforts in Japan have resulted in a two-pulse starting technique to achieve a smooth transition to steady state operation (ref. 12). Thruster breakdown voltages versus plenum pressure for various gases were reported. Furthermore, a two dimensional arcjet incorporating a quartz window was used to visually investigate the transition from initial breakdown to steady state operation as well as operation in the high and low voltage modes.

To date, there has been limited investigation of the use of impulse breakdown for arcjet ignition. Impulse breakdown itself is a complex and not we 11 understood process. In addition, actual arcjet thruster breakdown characteristics are complicated by vortex flow gas dynamics, complex electrode geometries, surface condition and temperature, and strong gas pressure gradients. However, impulse breakdown arcjet ignition has proven to be a practical starting technique. The major objective of this experimental work was the ignition characterization of a $1 \mathrm{~kW}$ class arcjet using a laboratory pulser integral with a pulse width modulated power supply.

The impulse breakdown characteristics of arcjets were investigated. Breakdown voltages as functions of propellant flow rate, electrode spacing, and pulse voltage rate of rise were experimentally determined for hydrogen/nitrogen mixtures. Statistical variations were found to occur in breakdown voltages. 
Furthermore, occasional postbreakdown phenomena such as glow discharge occurred. The impact of these phenomena is assessed.

\section{NOMENCLATURE}

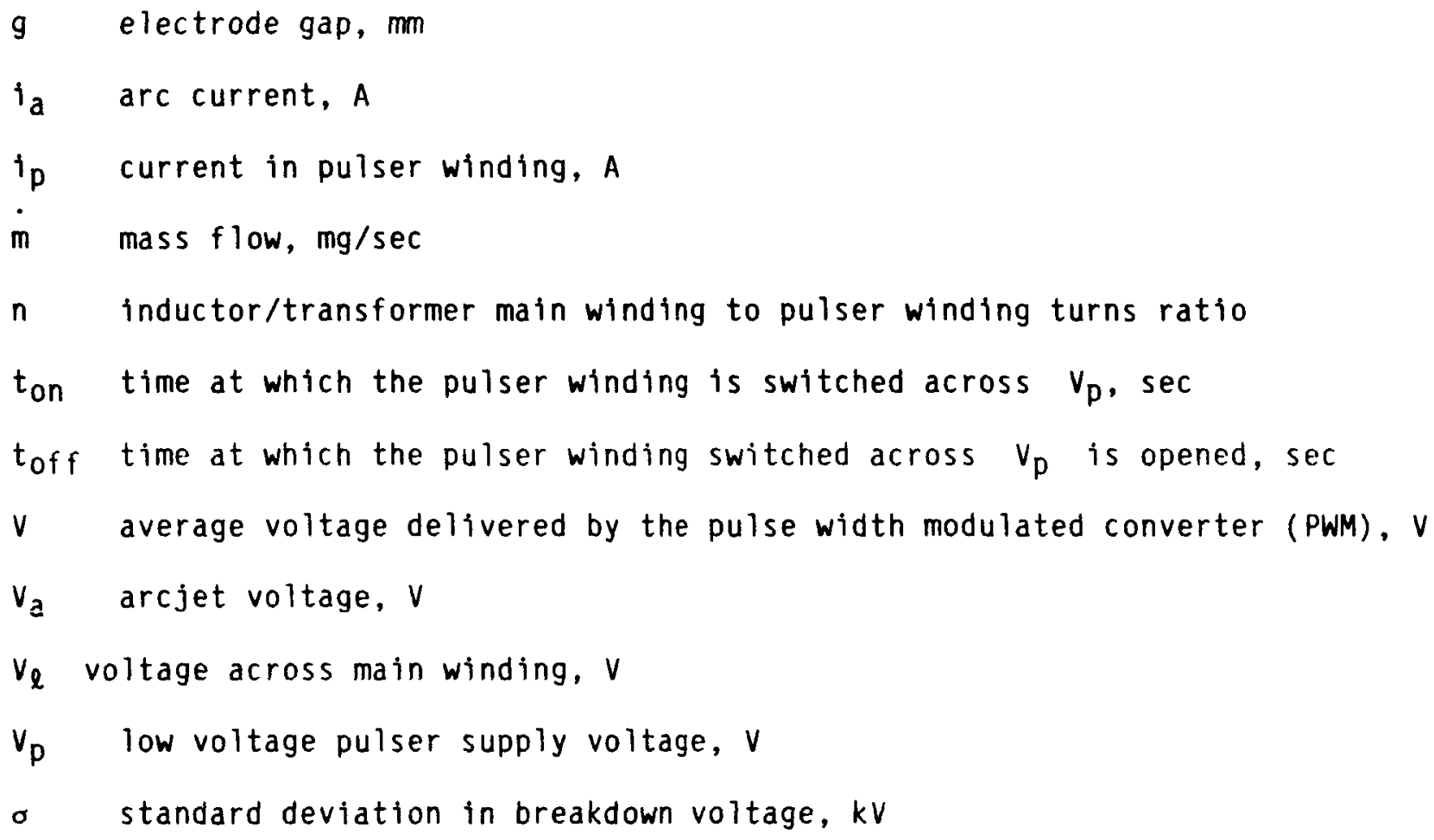

\section{APPARATUS}

Thruster

The arcjet thruster used in these tests was a conventional constricted, vortex-stabilized design (fig. 1). A thoriated tungsten insert with a constrictor $0.64 \mathrm{~mm}$ in diameter and $0.25 \mathrm{~mm}$ in length served a dual purpose as both anode and expansion nozzle. Its converging half angle (chamber) was $30^{\circ}$, and its diverging half angle (nozzle) was $20^{\circ}$, with an area ratio of $\sim 750$. The cathode consisted of a $3.2-\mathrm{mm}$ diameter thoriated tungsten rod tapered to a $26^{\circ}$ half angle at the tip. It was anchored in position by a modified swagelok fitting held into the rear insulator. Vortex stabilization was accomplished by two $0.25-\mathrm{mm}$ diameter holes separated by $180^{\circ}$ injecting gas tangentially into a 6.4-mm diameter arc chamber. With this design, all propellant was directed through these tangential holes in order to maximize vortex intensity.

The anode, cathode, and injection disk were contained inside a stainiess steel anode housing. The walls of the housing served as a radiant heat sink through which the propellant and anode current were passed. A rear insulator was bolted to the anode housing to compress the internal arrangement into a gas tight assembly.

Electrode gaps were set without disassembling the thruster. The Swagelok fitting at the rear of the thruster was loosened such that the cathode could 
be pushed to contact the anode. The cathode was then withdrawn the desired gap distance and the Swagelok fitting tightened, securing the cathode in position. This procedure ensured that cathode tip centering was maintained within an estimated $0.05 \mathrm{~mm}$ of the constrictor centerline.

\section{Power Processor and Pulse Ignitor}

The arcjet power electronics system used for this investigation was similar to the power conditioner described in earlier work (ref. 9). The pulse ignition circuitry was modified to provide a more flexible laboratory tool instead of being representative of flight type circuitry. A simplified diagram of the laboratory pulser is shown in figure 2. Typical simplified waveforms detailing pulser operation are given in figure 3. Further pulser details can be found in appendix $A$.

The laboratory pulser uses a separate voltage source for pulse power. This provision allows operation of the pulser with the pulse width modulated (PWM) converter turned on or off. Basic pulser operation is similar to that used previousiy (ref. 9). Referring to figures 2 and $3(a)$, the pulser winding of the pulse transformer/averaging inductor is switched across a low voltage source at time $t_{\text {on. }}$. The pulser winding current, ip increases almost linearly with time until $t_{\text {off }}$ is reached, then the switch is opened. At that instant, the current in the pulser winding starts flowing through the diode and into the capacitor. The capacitor current can be considered a decreasing cosinusoid with a maximum value occurring at $t_{\text {off }}$. The corresponding capacitor voltage then increases sinusoidally until the current in the pulser winding reaches zero. The diode prevents the charged capacitor from reversing the current in the pulser winding. The voltage across the pulser winding during the time that the capacitor is being charged is the sum of the low voltage source plus the capacitor voltage. The voltage across the pulser winding multiplied by the inductor/pulse transformer turns ratio, $n$ appears as $v_{\ell}$ across the main winding. After the capacitor is charged through the diode, the pulser winding sees an open circuit and $V_{\ell}$ drops to zero. A high value shunt resistor (not shown in fig. 2) was used to discharge the capacitor in preparation for the next pulse. The family of open circuit pulses used for this investigation is shown in figure 4. The peak current in the pulser winding was set at about $85 \mathrm{~A}$ for all the work described in this paper.

Figure 3(b) shows pulser operation for a typical breakdown with the PWM turned off. $V_{\ell}$ drops to a value determined by the thruster and its propellant as well as the initial current, $i_{a}$. For some types of postbreakdown discharge, such as glow discharge, the voltage stays almost constant with varying current. At initial breakdown, the drop in thruster voltage appears across the main inductor winding. This voltage drop is reflected to the pulser winding. The reduced voltage at the pulser winding causes current to stop flowing through the diode and into the capacitor since the capacitor voltage is suddenly higher than the sum of the low voltage source, $v_{p}$ and the pulser winding voltage, $V_{\ell} / n$. Reverse current is blocked by the diode.

For the case where the PWM is turned on and breakdown occurs to a thruster discharge voltage greater than the PWM voltage, the main winding current will decay to zero and ignition will not take place. As evident from figure $3(\mathrm{c})$ ignition can occur only when the arcjet discharge voltage, $v_{a}$, is less than the PWM output voltage, V. 


\section{Electronic Timer}

An electronic timer was developed for use with the power processor and pulse ignitor. The timer enabled cyclic operation with predetermined oN and OFF times. The power processor and pulse ignitor $+15 \mathrm{~V}$ control circuit power was routed through an external connector. For normal operation, the connector was short circuited. Where the timing function was needed, a transistor switch controlled by the timer was placed in series with the $+15 \mathrm{~V}$ control circuit power using the connector.

The timer incorporated a current transformer to sense thruster ignition and allowed the thruster to operate for a preset time. At the end of that time, another preset timer determined the delay until the power processor and pulse ignitor were again turned on. Both timers were adjustable from $0.1 \mathrm{sec}$ to $999.9 \mathrm{sec}$ in $0.1 \mathrm{sec}$ steps. In addition, a manual mode was available for tests where only the on time adjustment must be made and recycle must be operator initiated.

Vacuum Facility

All tests were performed in the tank 8 vacuum facility at NASA Lewis Research Center (ref. 3). This tank is $1.5 \mathrm{~m}$ in diameter, $5 \mathrm{~m}$ long, and serviced by four 30000 liter/min oil diffusion pumps. Pumping speeds were such that during maximum propellant flow (typically $50 \mathrm{mg} / \mathrm{sec}$ ), the ambient vacuum conditions never exceeded $5 \times 10^{-4}$ torr. The arcjet to be tested was located within a $0.9-\mathrm{m}$ diameter by $0.9 \mathrm{~m}$ long port extension at one end of the tank. This gave the thruster unobstructed access to the main tank during operation but also allowed for port isolation with a $0.9 \mathrm{~m}$ gate valve.

\section{Propellant Feed System}

Propellant supplied to the arcjet thruster consisted of hydrogen and nitrogen gas mixtures at a ratio equal to that of fully decomposed hydrazine. The hydrogen had a purity $>99.9995$ percent, containing <1 ppm oxygen and <1 ppm water, while the nitrogen was of a purity $>99.999$ percent, containing <1 ppm oxygen and $<3 \mathrm{ppm}$ water. The two gases were stored separately and each regulated down to 1.0 MPa for final metering and mixing in a propellant flow panel.

At the tank 8 facility, propellant flow measurements were made using thermal laminar flow type transducers and were displayed on the flow panel with digital readouts. Each transducer had a full scale flow output of 5.00 standard liters/min (SLPM). Final gas flow rates were set with and maintained by an automatic mass flow controller. Simulated decomposed hydrazine required a $2: 1$ standard volume ratio of hydrogen to nitrogen.

An important part of the propellant flow system was a sonic orifice in the gas line immediately upstream of the arcjet (fig. 1). This orifice prevented flow rate transients due to arc ignition from propagating upstream through the flow system. Without this type of isolation, mass flow through the arc would be temporarily reduced while the entire flow system built up pressure. The sonic orifice allowed for a fast pressure response during starting and permitted rapid transition to steady state thruster operation, usually within a fraction of a second. 


\section{Data Recording}

Experimental data obtained include arc voltage, current, propellant flow rates, and inlet pressure. These signals were recorded on an eight channel chart recorder with a bandwidth of about $150 \mathrm{~Hz}$. A $100 \mathrm{~V}$ Zener diode was used in conjunction with a resistive voltage divider to block high-voltage pulses from the chart recorder input. Cross-channel noise problems were prevented through the use of isolation amplifiers and shielded cable.

An analog storage oscilloscope with differential voltage inputs and a single ended input fed from a current transformer were used to observe high speed voltage and current transients. Arcjet voltage was measured using identical differential voltage probes having bandwidths of dc to $25 \mathrm{MHz}$. The voltage probes were adjusted to provide the same high speed response. The degree of accuracy at high frequencies depended upon precise manual adjustment. High frequency common mode error was estimated by connecting both probes to the high voltage open circuit positive pulse output and found to be negligible. The current transformer used to measure short duration current transients had a scale factor of $0.1 \mathrm{~V} / \mathrm{A}$ and bandwidth of $120 \mathrm{~Hz}$ to $20 \mathrm{MHz}$.

\section{EXPERIMENTAL PROCEDURE}

The high voltage pulse ignition of an arcjet thruster depends on (1) successful predischarge ignition (breakdown of the electrode gap) and (2) successful transition to a sustained discharge following breakdown. Both aspects of the ignition process were examined in this investigation. The dependence of breakdown voltage (BDV) on electrode gap, gas flowrate, and voltage rate of rise was studied by applying the high-voltage pulses to the arcjet electrodes with the PWM turned off. This was done to prevent a sustained discharge following breakdown and, thereby, separate initial ignition characteristics from conditioning effects associated with arcjet operation. For the purposes of this paper, this will be referred to as spark testing or sparking and the resulting transient electrical discharges (fig. 5) as sparks. In another part of the test, referred to as hot start testing, the PWM was turned on so the arcjet could be cycled on (started) and off while the breakdowns were monitored as the thruster heated up. The effort here was directed toward isolating whether reignition difficulties previously experienced with hot thrusters (ref. 13) (immediately following extended operation) were associated with the breakdown or transition phase of ignition.

Following initial assembly, the arcjet used for this investigation was not disassembled until the completion of all testing. This helped avoid any changes in electrode configuration or gas seal integrity. As mentioned previously, gap adjustments were made while the thruster remained fully assembled. When arcjet ignition testing was finished, the thruster was taken apart and the internal elements carefully examined. Scanning electron microscope (SEM) photographs were then taken of the cathode and anode to reveal surface textures and features which might affect Bov levels.

BDVs were measured by capturing the high-voltage pulses with an analog storage oscilloscope. This technique was used for impulse breakdowns in lower pressure systems (ref. 14). The differential probes used for these measurements were checked for proper compensation prior to each test to ensure accur.. ate attenuation of the transient voltages measured with the oscilloscope. 
Breakdown voltages determined from each oscilloscope trace were grouped to the nearest $0.05 \mathrm{kV}$ (half a small division) and subsequently averaged. Consecutive pulses were timed to avoid erroneously low breakdown voltages resulting from localized heating effects of previous breakdowns. A time delay of approxi. mately $15 \mathrm{sec}$ between pulses was used for all spark tests, though experience indicated a few seconds was sufficient.

Following some preliminary spark testing, the arcjet was operated for $1 \mathrm{hr}$ at a mass flow of $45.2 \mathrm{mg} / \mathrm{sec}$ and a current of $10 \mathrm{~A}$ to burn-in the newly machined cathode. During this burn-in period, the cathode tip is known to undergo change as it melts and assumes a new shape which soon stabilizes. Once cool, the arcjet electrodes were then preconditioned by sparking before BDV testing was begun.

To determine how BDV varied with electrode gap, pulse $P 1$ ( $f i g .4$ ) was used at a mass flow of $45.2 \mathrm{mg} / \mathrm{sec}$ for various gaps from 0.36 to $0.93 \mathrm{~mm}$. This range corresponds approximately to that over which stable nondestructive operation has thus far been obtained with this thruster for the electrode dimensions and mass flows used here. However, gap settings from 0.51 to $0.64 \mathrm{~mm}$ have been the most often used.

The BOV versus gap data were acquired immediately following each gap adjustment with the exception of the $\mathrm{g}=0.57 \mathrm{~mm}$ case. This was the original gap at which initial burn-in and subsequent spark testing and hot start testing was conducted. In this particular case, the BDV versus gap test was the last at this gap. However, in all cases, the arcjet had been exposed to air just prior to BDV vs. gap testing. For each gap, the first 100 spark BDVs were recorded. Then, about 370 more sparks at the rate of $74 / \mathrm{m} i n$ were applied in order to further clean/condition the electrode surfaces. After an additional 4 min wait, during which no sparks were passed, another 100 BDVs (470 to 570 th) were recorded.

The influence of voltage rate of rise on BDV was examined using various pulses ( $P 1$ to $P 6$ in fig. 4), each with a different voltage rise time and peak voltage, at a mass flow of $45.2 \mathrm{mg} / \mathrm{sec}$ and gaps of 0.57 and $0.59 \mathrm{~mm}$. The data corresponding to the $0.57 \mathrm{~mm}$ gap were taken prior to the hot start testing period, while that corresponding to the $0.59 \mathrm{~mm}$ gap were taken subsequent to this period.

BDV versus mass flow data were taken at three gaps, $0.45,0.57$, and $0.93 \mathrm{~mm}$ using pulse $\mathrm{Pl}$. At each gap, the $\mathrm{N}_{2}: 2 \mathrm{H}_{2}$ mixture mass flow was varied from 5.6 to $50.4 \mathrm{mg} / \mathrm{sec}$. This flow range extends well below that at which the thruster has been started or operated in a stable, nondamaging manner. Spark testing was extended to these low mass flows in order to further investigate the apparent and unexpected trend of increasing BDV with decreasing mass flow.

Throughout all testing, careful attention was paid to detecting changes in BDV levels resulting from exposure to air, spark conditioning, or powered operation. An effort was made to separate and minimize the effect of these factors on BDV data involving gap, mass flow, and high-voltage pulse variation. Part of this effort consisted of keeping a detailed chronology of the mean BDV levels. Also, when the electrodes were exposed to air, a spark conditioning phase was conducted prior to further testing. BDVs from such a conditioning phase are presented with the BDV versus gap data. 


\section{Cold Thruster Breakdown Tests}

The statistical nature of impulse breakdowns observed during this investi gation required that a number of BDVs be recorded for each set of parameters ( $1 . e .$, gap, mass flow, and pulse voltage rate of rise). Measures (e.g., mean) of the resulting BDV distributions could then be calculated and compared for various parameter variations. Only then was it possible to clearly define trends in BDV with a given parameter. Figure 6 shows a representative BDV distribution. The BDV distribution means, standard deviations, and ranges in general depended on the set of parameters for which they were obtained. However, their form usually resembled that of figure 6 , being slightly skewed toward higher voltages. Typically, the relative dispersion as measured by the coeffi. cient variation (standard deviation divided by mean) was between 2 and 6 percent.

Figure 7 demonstrates the dependence of BDV on electrode gap for the application of pulse Pl at a mass flow of $45.2 \mathrm{mg} / \mathrm{sec}$. As figure 7 shows, the mean BOV increased nearly linearly with gap over most of the range investi. gated. At the largest gap tested, however, there appeared to be a slight departure from this trend toward a slower increase in BDV with gap. It is also noteworthy that the largest scatter as measured by the standard deviation or range in BDVs occurred for the largest and smallest gaps.

Mean BDVs from the spark conditioning phase conducted after each exposure to air during gap adjustment were also monitored. These are included in figure 7. Comparison of the open and closed symbols shows that mean BDVs were slightly higher during initial sparking than after a period of spark condition. ing. This was found to be a common experience following exposure to air. A few hundred sparks were usually found to be sufficient to stabilize the mean BDV.

Figure 8 displays the dependence of mean BOV on pulses of various rates of voltage rise for a mass flow of $45.2 \mathrm{mg} / \mathrm{sec}$ at gaps of $0.57 \mathrm{~mm}$ (open circles) and $0.59 \mathrm{~mm}$ (closed circles). Since the pulses used in this investigation have somewhat nonlinear rates of rise, some question arose as to how to define the average rate of voltage rise for each pulse. It was judged that the most meaningful average rate of rise would be that between the static BDV level for these conditions and the mean BDV corresponding to a given pulse. However, the static BDV was not known. Therefore, the lowest BDV, $1.0 \mathrm{kV}$, observed with any of the pulses, PI to P6, was used instead of the static BDV. For the test at each gap, the mean BDV clearly increased with increasing rate of voltage rise. The difference in BDV levels between the test at each gap is not accounted for by the gap difference, as reference to figure 7 indicates. As mentioned in the procedure section, the test at $\mathrm{g}=0.57 \mathrm{~mm}$ was conducted prior to the hot start testing period while the test at $\mathrm{g}=0.59 \mathrm{~mm}$ was conducted after this period. Mean BDV levels after the hot start testing period compared to before appear to have shifted upward a significant amount when compared to the variations with voltage rate of rise, gap, and mass flow seen during the spark tests. Since it is not felt that this shift can be explained by changes in instrument calibration or experimental conditions, it is possible that the shift may be a result of the hot start testing which involved hundreds of cycles. However, before such a conclusion could be drawn, further investigation is required. 
Figure 9 shows how the mean BDV was found to vary with mass flow for pulse $P 7$ applied at three gap settings. Essentially similar behavior was observed at all three gaps, with the mean BDV increasing, then decreasing, and again increasing with mass flow. The flow range from 30 to $54 \mathrm{mg} / \mathrm{sec}$ corresponds to that over which the thruster is usually started and operated. Over this range the mean BDVs varied less than $250 \mathrm{~V}$ at each gap. One may note that for a given mass flow the mean BDV for $g=0.45 \mathrm{~mm}$ in figure 9 (a) may exceed the mean BOV for $g=0.57 \mathrm{~mm}$ in figure $9(b)$, in apparent contradiction to the BDV vs gap data discussed earlier. However, the data in figure $9(b)$ were taken at the original gap prior to the hot start testing period, while that in figures 9 (a) and (c) was taken after this period. As noted before, a shift upward in BDVs appeared to have occurred during this time. This shift accounts for the apparent discrepancy.

\section{Hot Thruster Starting Tests}

For these tests, the thruster temperature was increased by operating the power processor and pulse ignitor with the PWM converter turned on and set to supply 10 A steady state current to the thruster. Thruster temperature, meas. ured on the outside of the anode housing near the nozzle, was kept in the 300 to $500{ }^{\circ} \mathrm{C}$ range by cycling the thruster. The maximum continuous operating steady state temperature for the same conditions was found from previous experiments to be about $930{ }^{\circ} \mathrm{C}$ for the 33.6 to $45.2 \mathrm{mg} / \mathrm{sec}$ mass flow range and $10 \mathrm{~A}$ current used here. For cold starts, the thruster always started on the very first pulse for all pulses PI through P6. Hot starts occasionally required two or more pulses to achieve successful ignition. Further investigation of this phenomenon revealed that a breakdown always occurred but was not always sustained. This tendency was more pronounced with the lowest voltage pulse, P6. Figure 10 shows two typical breakdowns. In one (fig. 10(a)), the postbreakdown discharge voltage remained below the $180 \mathrm{~V}$ PWM output voltage and the discharge was sustained. In the other ( $\mathrm{fig} .10(\mathrm{~b})$ ), the postbreakdown discharge voltage rose above the PWM output voltage and the discharge was extinguished. Figure 11 also shows, using a factor of 10 shorter time scale, two other breakdowns which occurred with a slightly lower mass flow. One of the breakdowns (fig. $11(\mathrm{a})$ ) was a typical successful breakdown to a sustained low voltage discharge similar to that in figure 10(a). However, the other (fig. $71(\mathrm{~b})$ ) shows a breakdown to a $500 \mathrm{~V}$ discharge, which did not transition to a sustainable lower voltage discharge and, thus, was extinguished. Such postbreakdown high-voltage discharges which did not quickly transition to a lower voltage mode were not sustained. The reason for this is discussed in the power processor and pulse ignitor description and can be inferred from figures 2 and 3 . The discharge cannot be sustained when the arc discharge voltage, $v_{a}$, is less than the PWM output voltage, V. Breakdowns to $500 \mathrm{~V}$ discharges did not always result in ignition misfires. As shown in figure 12 , the $500 \mathrm{~V}$ discharges sometimes exhibited a distinct step transition to a lower voltage discharge in time for the discharge to maintained. The postbreakdown $500 \mathrm{~V}$ discharges have characteristics resembling high pressure glow discharges. The presence of occasional discharges that do not transition to a sustained discharge are not expected to cause severe difficulties since the pulser can be designed to deliver several pulses per second until discharge is sustained. High voltage discharges were not observed during the cold thruster breakdown tests. For the type pulser used, little energy is delivered to the potentialiy damaging glow discharge. 
Figure 1 (b) depicts approximately to scale the configuration of the burned-in cathode with respect to the chamber wall and constrictor at a gap, $g$ of $0.59 \mathrm{~mm}$. Recall that the definition of electrode gap used here refers to the axial distance the cathode has been withdrawn from contact with the anode. The minimum electrode separation (fig. 1(b)), corresponding to a given gap setting will be approximately half the gap distance (for the $30^{\circ}$ half angle chamber used here). This minimum separation will be reduced by whatever distance the cathode tip is off center. Based on cathode tip centering estimates mentioned earlier, it is believed that the reduction in minimum separation from half the gap setting was less than 20 percent for the smallest gap tested to less than 8 percent for the largest gap tested. In general, cathode tip misalignment will most likely lower the smallest BDV observed for given conditions. However, what effect it has on the mean BDV is not clear and may depend on the importance of spatiotemporal fluctuations in the breakdown initiation and development processes. How sensitive the BDV distributions measured here were to electrode alignment was not a subject of this investigation, but is deserving of further study.

Because it is known that changes in electrode surface condition can lead to appreciable differences in the observed breakdown characteristics of an electrode gap (ref. 15), it was considered important to document the electrode surface conditions at the conclusion of the test.

The shaded end of the tapered cathode cone in figure 1(b) represents where the cathode surface was roughened as a result of testing as shown by SEM in figure 13(a). The symmetry of this rough region indicates the cathode was we 11 aligned with the axis. Comparison of figure 13(d), which shows a portion of unaffected cathode surface, with figure 13(c), which shows a portion of the roughened surface, reveals the roughness to be a consequence of surface melting. From examination of figure $13(\mathrm{c})$, one can see that the rough region consists of many overlapping craters. Previous research involving spark tests with the high-voltage pulses used here has shown that while a single spark has a small effect on a polished cathode surface, the cumulative effect of several hundred sparks is sufficient to produce a surface morphology similar to that in figure $13(\mathrm{c})$ over an area of the cathode tip of the same extent as in figure 13(a). Numerous starts have a very similar effect (ref. 10). The primary difference in surface condition between a cathode that has been started and one that has been sparked several hundred times is the surface texture of the extreme tip. As shown in figure 13(b), a cathode following operation has a smooth bead at its extreme tip, while one that has been sparked numerous times will have the bead roughened to resemble the rest of the cathode tip region.

The anode chamber wall surface condition as revealed by SEM is shown in figure 14. This surface also appeared roughened. However, as can be seen from comparison of figures $14(b)$ and $13(c)$ this roughness has a different form than that of the cathode. The anode surface roughness appears to be a thin raised layer of rounded $\mu \mathrm{m}$ sized crystalline-like globes. This type of roughness would tend not to concentrate the surface electric field as much as that of the cathode would. 


\section{Cyclic starting tests}

Prior to the initial thruster assembly and breakdown tests described in the body of this report, a cyclic starting test was performed. The primary purpose of this test was to help investigate whether any undesirable characteristics in the process of thruster ignition and transfer to steady state would cause life limiting erosion or damage. The thruster was turned on for $3 \mathrm{sec}$ and off for $3 \mathrm{sec} 11600$ times. The test is described and results are presented in appendix $B$. Breakdown was initiated on the first pulse for all but two starts, where a second pulse was necessary for ignition.

\section{CONCLUSIONS}

An investigation of the pulse ignition characteristics of a $1 \mathrm{~kW}$ class arcjet using an inductive energy storage pulse generator integral with a pulse width modulated power converter identified several thruster and pulse generator parameters affecting breakdown voltages and ignition. Over all ranges of thruster and pulser parameters investigated, the mean breakdown voltage varied from 1.4 to $2.7 \mathrm{kV}$. There were substantial differences in standard deviations, but breakdown always occurred at voltages less than $3.5 \mathrm{kV}$. Mean breakdown voltage versus electrode gap exhibited a linear increase with gap. Mean breakdown voltage increased $300 \mathrm{~V}$ for average rates of voltage rise from about 0.1 to $0.8 \mathrm{kV} / \mathrm{ssec}$, at a nominal propellant flow rate of $45 \mathrm{mg} / \mathrm{sec}$. Mean breakdown versus flow varied substantially for propellant flow rates ranging from about 6 to $50 \mathrm{mg} / \mathrm{sec}$.

Ignition tests at elevated thruster temperatures using low rate of voltage rise pulses revealed occasional breakdowns with thruster discharge voltages higher than the average power converter output voltage. These breakdowns would not transition to the lower discharge voltage arc mode and the thruster would not ignite. Under the same conditions, a transition to the arc mode would occur for a subsequent pulse and the thruster would ignite.

An automated 11600 cyclic starting and transition to steady state test required application of a second pulse to initiate ignition only two times. Furthermore, no thruster damage or erosion was observed following the 11600 starts and transitions to steady state operation.

\section{ACKNOWLEOGMENT}

The authors gratefully acknowledge Robert Gott for his design and delivery of the electronic timer. 
The purpose of this appendix is to provide more detailed information to supplement the pulser discussion in the text. A schematic diagram of the pulser used for this work is shown in figure Al. Basic operation is described in the text. Two parallel power transistors comprise the switch used to connect the pulser to the $24 \mathrm{~V}$, low voltage source, $V_{p}$. The switch is actuated using one-half of a CD4098B dual one-shot multivibrator with an adjustable pulse width having a range of about 20 to $120 \mu \mathrm{sec}$. This technique adjusts the peak current in the pulser winding over a range of about 20 to $100 \mathrm{~A}$. So, at the instant of breakdown, the maximum possible initial arc current in the main winding corresponding to the maximum current in the pulser winding is adjustable from about 2 to $11 \mathrm{~A}$.

The size of the capacitor that the pulser winding current flows into determines the maximum pulse voltage for a given peak current as well as pulse rate of voltage rise. Capacitance was variable from 0 to $3.6 \mu \mathrm{F}$ using switched capacitors. The capacitors had a negligible effect on steady state and transient PWM operation. The maximum pulse voltage capability was about $5 \mathrm{kv}$ and is limited by the power transistors maximum drain to source voltage of $400 \mathrm{~V}$.

The pulse repetition rate is determined by adjusting the timing resistor for the other one shot multivibrator in the CD4098B. As described in earlier work (ref. 9), the circuit also turns off the pulser when sufficient arc current, $i_{a}$ is detected. A transformer coupled synchronization pulse is provided for oscilloscope timing at the transistor on and of $t$ times.

Component layout and inductor design were not optimized for the rapidiy changing currents and voltages in this laboratory pulser. Instead, a smoothiy varying pulse and protection for the power transistors was accomplished using two resistor capacitor networks as shown in figure Al. In addition to pulse smoothing, the resistor capacitor network connected directiy across the arcjet has two effects on pulser operation:

(1) The open circuit pulse voltage decreases less abruptly after maximum voltage is reached.

(2) The capacitor resistor network increases the avallable current at breakdown for about $0.5 \mathrm{\mu sec}$.

The pulser is a laboratory tool that allows both the maximum open circuit voltage and the current available at the instant of breakdown as well as pulse voltage rate of rise to be adjusted for the purposes of investigating impulse breakdown in arcjets. 
An automated cyclic starting test was implemented to heip determine whether the process of hot thruster ignition and transfer to steady state would cause life limiting erosion or damage and to demonstrate the feasibility of off-pulsing operation for spacecraft attitude control.

The thruster was mounted in a 0.46 m vertical bell jar facility described elsewhere (ref. 11). Electrodes of the same dimensions as those used elsewhere in this report, and which had previously accumulated 260 starts, were employed. A thermocouple was attached to the thruster body near the nozzle end using stainless steel wire. The other apparatus used were described previousiy in this report. For this test, the electronic timer was used with the power processor and pulse ignitor. The propellant was a 2:1 ratio of hydrogen:nitrogen at a flow rate of about $45 \mathrm{mg} / \mathrm{sec}$. Flow rate was maintained using closed-loop flow controllers. Propellant flow was left on continuously and current was set at $10 \mathrm{~A}$.

Pulse PI was used throughout the test and the thruster started on the first pulse except for two occasions where a second pulse was needed for ignition. Thruster body temperature averaged $430{ }^{\circ} \mathrm{C}$ and varied between 410 and $450{ }^{\circ} \mathrm{C}$ after about $1.5 \mathrm{hr}$ of cycling. From previous experience, maximum temperature for continuous operation at $10 \mathrm{~A}$ would have been $930^{\circ} \mathrm{C}$.

The thruster was disassembled and inspected before and after the 11600 cycle test. The cathode and the anode insert were examined with an SEM. SEM photographs (figs. BI and B2) showed no visible damage or erosion from the 11600 ignitions and transfers to steady state power levels. 


\section{References}

1. Wallner, L.E. and Czika, J., Jr., "ArC-Jet Thrustor for Space Propulsion," NASA TN D-2868, 1965.

2. Knowles, S.C., Smith, W.W., Curran, F.M., and Haag, T.W., "Performance Characterization of a Low Power Hydrazine Arcjet," AIAA Paper 87-1057, May 1987.

3. Nakanishi, S., "Performance Evaluation of a 1 Kilowatt Arcjet Thruster," AIAA Paper 85-2033, Sept. 1985. (NASA TM-87131).

4. Ducati, A.C., Humpa 1, H., Me1tzer, J., Muehlberger, E., Todd, J.P., and Waltzer, H., "l-KW Arcjet-Engine System-Performance Test," Journal of Spacecraft and Rockets, Vol. 1, No. 3, May-June, 1964, pp. 327-332.

5. McCaughey, 0.J., Geideman, W.A., Jr., and Muller, K., "Research and Advanced Development of a 2 KW Arc-Jet Thrustor," GRC-1646, Plasmadyne Corp., Santa Ana, CA, 1963. (NASA CR-54035).

6. Curran, F.M. and Nakanishi, S., "Low Power dc Arcjet Operation with Hydrogen/Nitrogen Propellant Mixtures," AIAA Paper 86-1505, June 1986, (NASA TM-87279).

7. Byers, D.C. and Wasel, R.A., "The NASA Electric Propulsion Program," AIAA Paper 87-1098, May 1987. (NASA TM-89856).

8. Knowles, S.C., Smith, W.W., Chun, S.I., and feconda, R.T., "Low Power Hydrazine Arcjets: A System Description for Near Term Application," 1986 JANNAF Propulsion Meeting, Vol. 1, K.L. Strange and D.S. Eggleston, eds., CPIA-PUBL-455-VOL-1, Chemical Propulsion Information Agency, Laure 1, MD, 1986, pp. 399-408.

9. Gruber, R.P., "Power Electronics for a 1-Kilowatt Arcjet Thruster," AIAA Paper 86-1507, June 1985. (NASA TM-87340).

10. Curran, F.M. and Haag, T.W., "Arcjet Component Conditions Through a Multistart Test," AIAA Paper 87-1060, May 1987. (NASA TM-89857).

11. Haag, T.W. and Curran, F.M., "Arcjet Starting Reliability: A Multistart Test on Hydrogen/Nitrogen Mixtures," AlAA Paper 87-1061, May 1987. (NASA TM-89867).

12. Yoshikawa, T., Onoe, K., Ohba, T., Yoshida, H., Suzuki, H., and Marimota, S., "Development of a Low Power dc Arcjet for Space Propuision," AIAA Paper 87-1058, May 1987.

13. Wintucky, E.G. and Gruber, R.P., "Pulse Ignition Characterization of Mercury Ion Thruster Hollow Cathode Using an Improved Pulse Ignitor, "AIAA Paper 78-709, Apr. 1978. (NASA TM-78858).

14. Curran, F.M., Private Communication, NASA Lewis Research Center, Cleveland, $\mathrm{OH}, 1987$.

15. Meek, J.M. and Craggs, J.D., "Electrical Breakdown of Gases," Clarendon Press, London, England, 1953. 


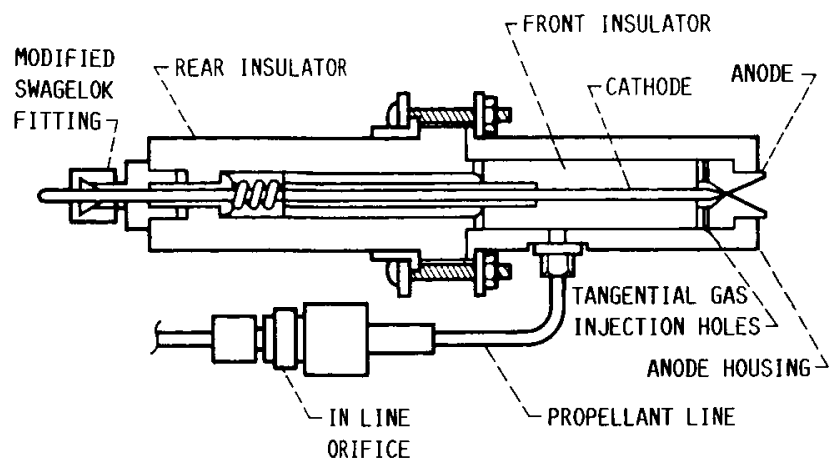

(A) CROSS SECTIONAL SCHEMATIC OF ARCJET.

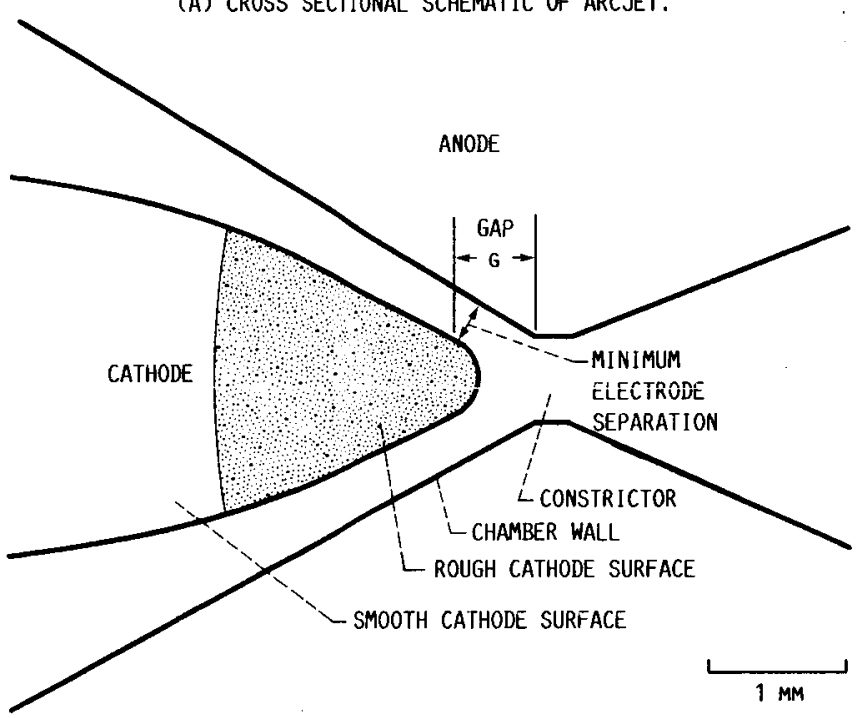

(B) ENLARGED CROSS SECTIONAL VIEW OF CATHODE IIP-CONSTRICTOR REGION. FIGURE 1. - CUTAWAY VIEWS OF ARCJET.

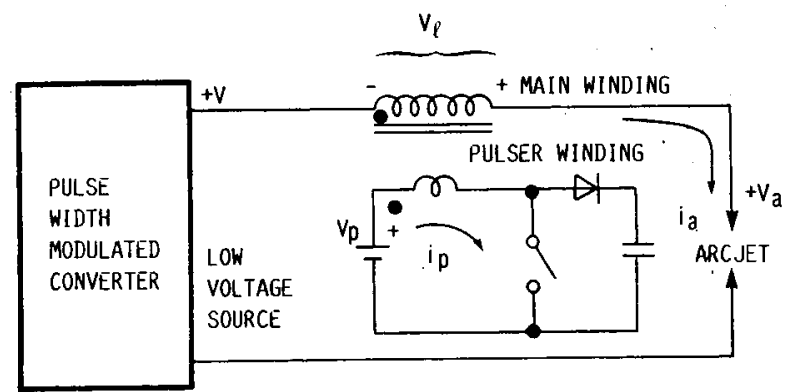

FIGURE 2. - SIMPLIFIED DIAGRAM OF PULSER. 

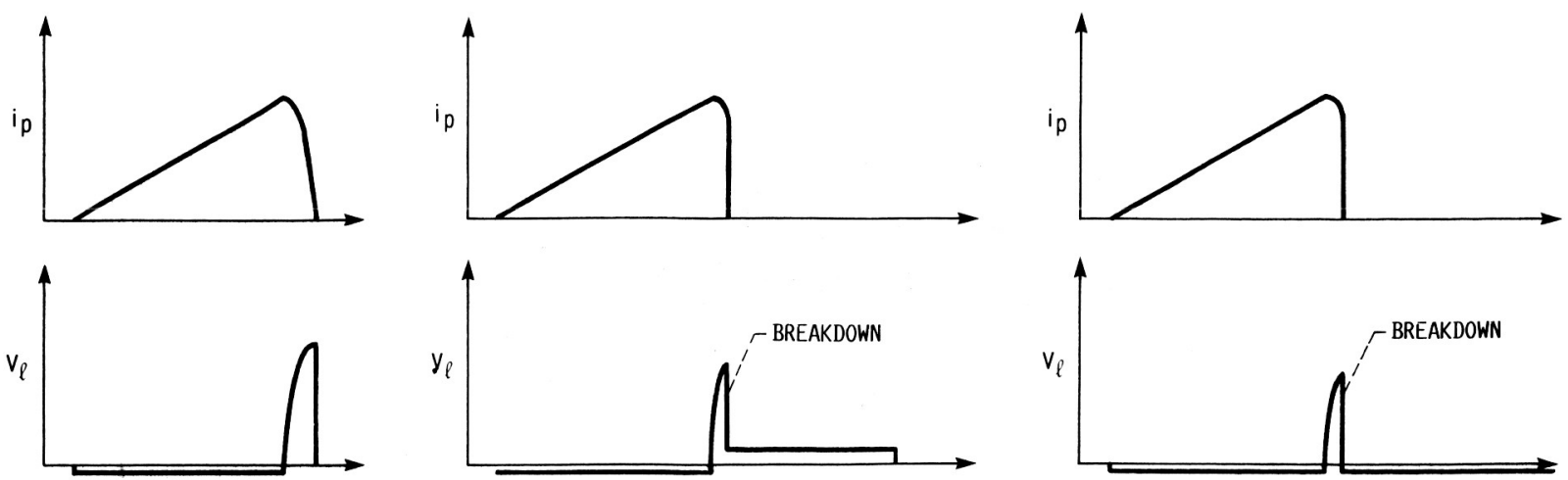

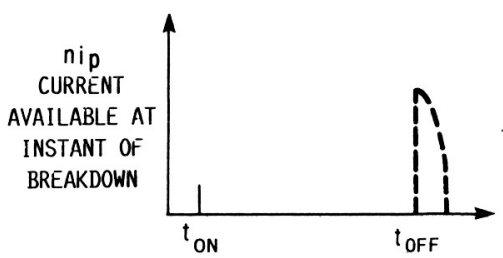

(A) NO BREAKDOWN, OPEN CIRCUIT.

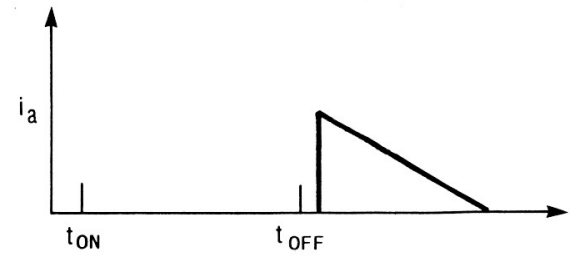

(B) TYPICAL BREAKDOWN, PWM OFF $O R V_{a}>V$.

FIGURE 3. - SIMPLIFIED PULSER WAVEFORMS.

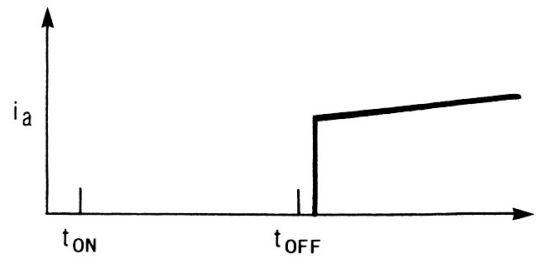

(C) TYPICAL BREAKDOWN, PWM ON AND $V>V_{a}$.

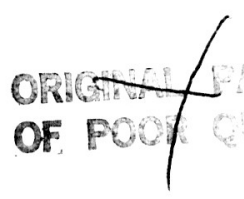

ORIGNAL PAGE IS OF POOR QUALITY

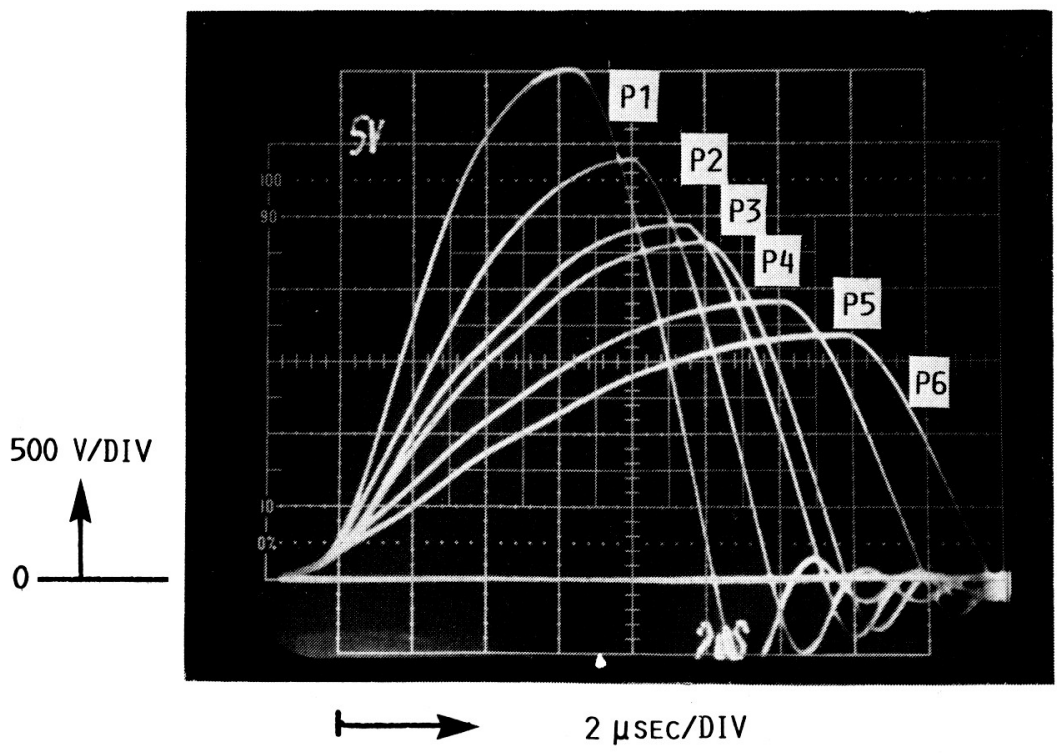

FIGURE 4. - OSCILLOSCOPE TRACE OF THE OPEN CIRCUIT PULSES P1 THROUGH P6. 


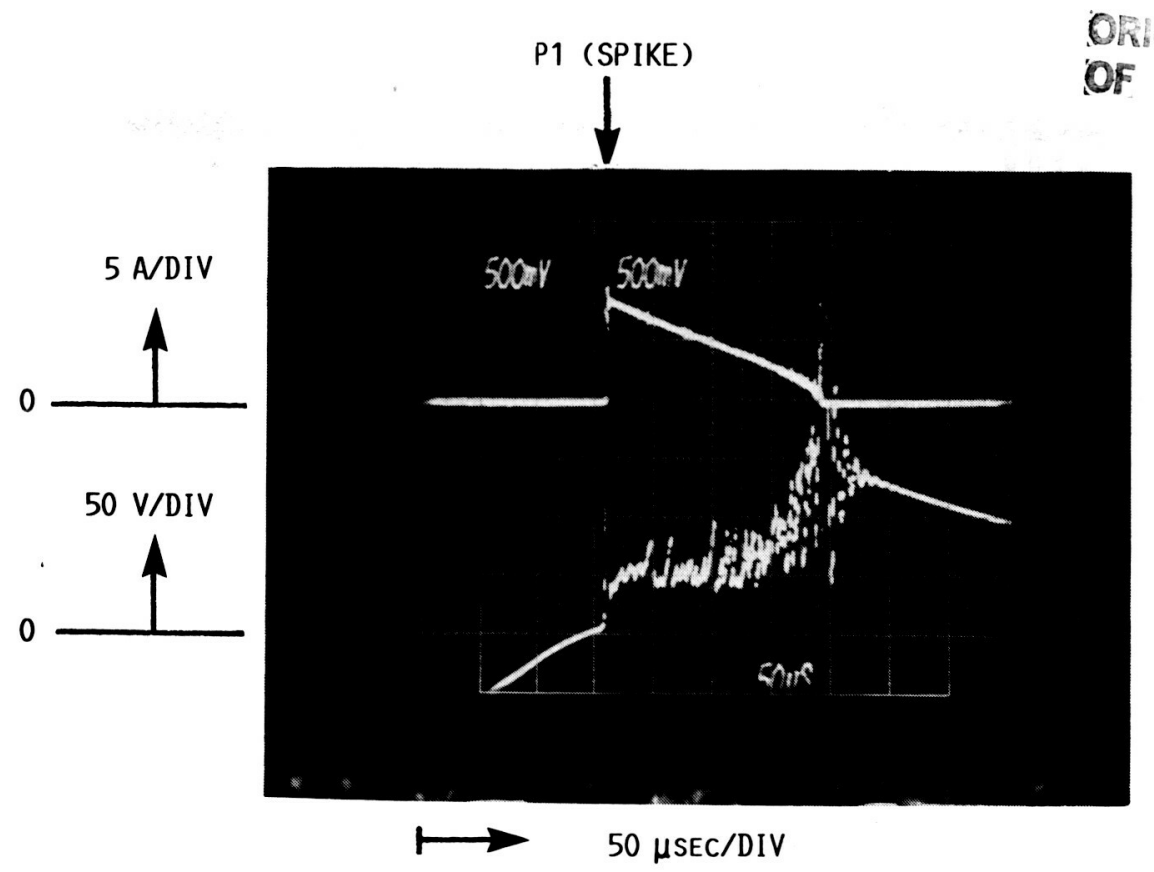

FIGURE 5. - OSCILLOSCOPE TRACE OF THE DISCHARGE VOLTAGE (LOWER TRACE) AND CURRENT (UPPER TRACE) FOR A TYPICAL BREAKDOWN WITH THE PWM OFF (SPARK). PULSE P1 WAS APPLIED AT $G=0.57 \mathrm{MM}$ AND $\dot{M}=45.2 \mathrm{MG} / \mathrm{SEC}$.

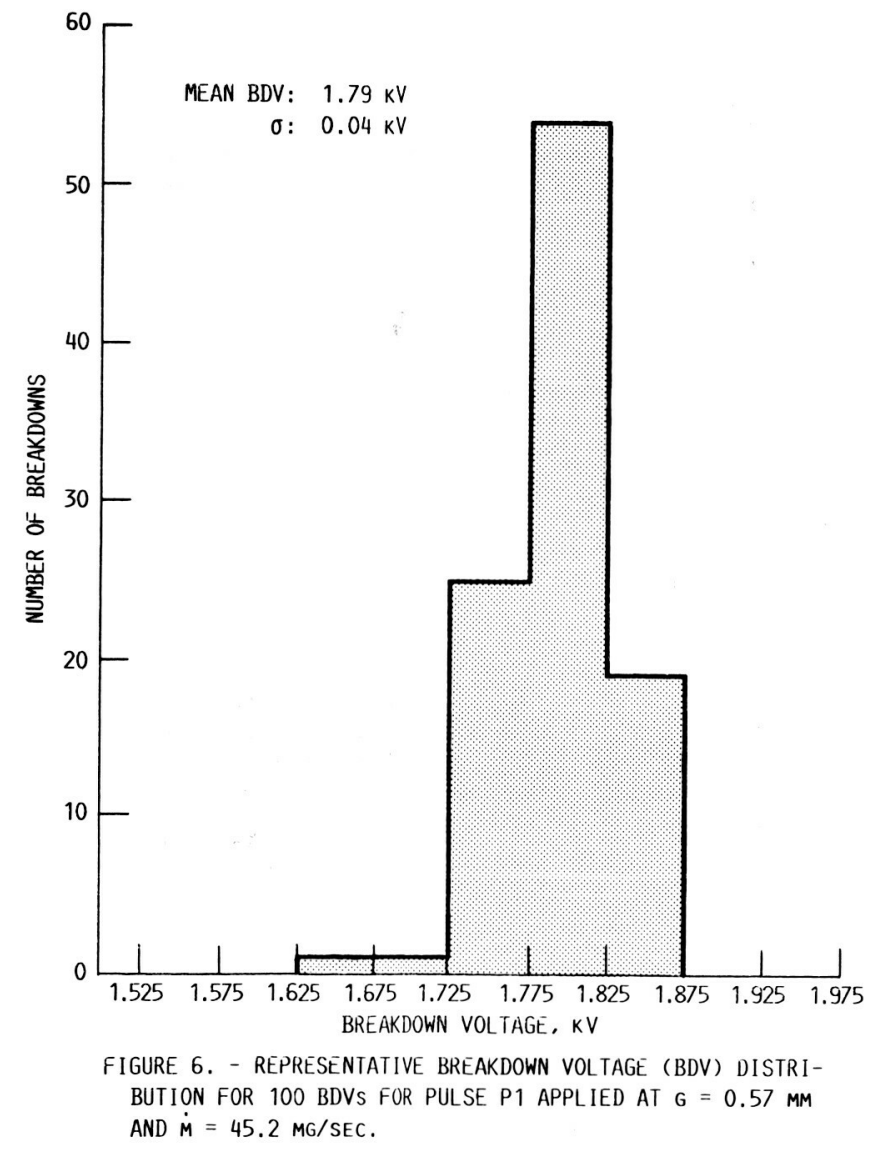




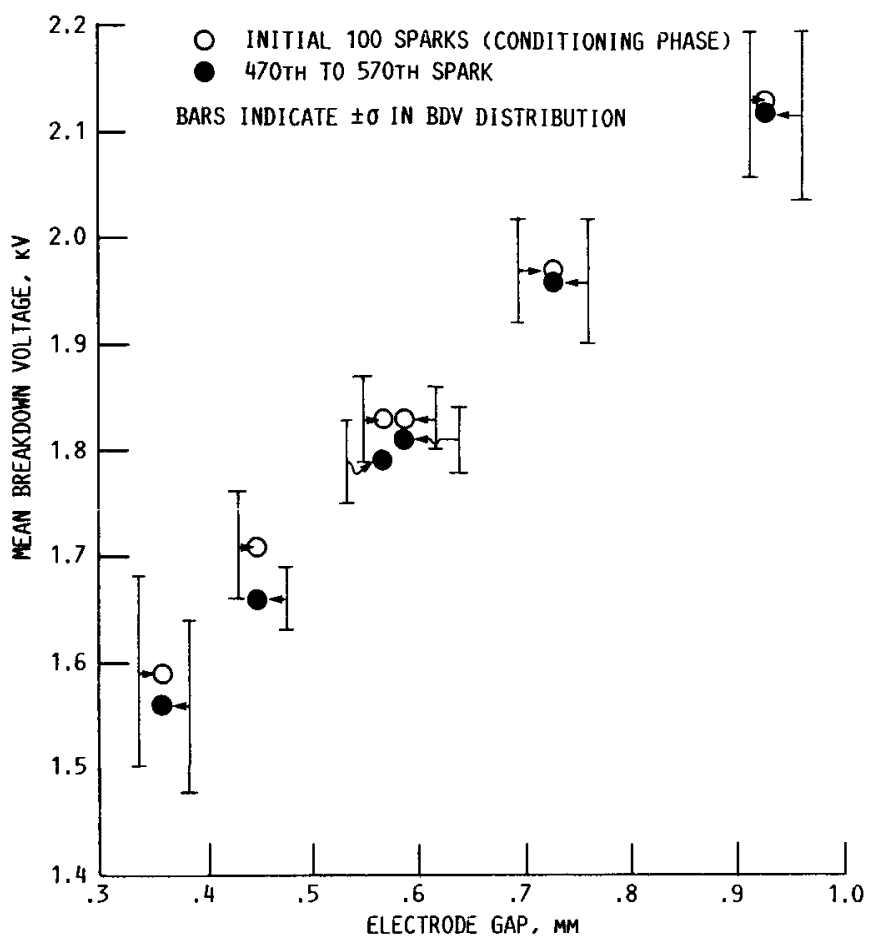

FIGURE 7. - MEAN BREAKDOWN VOLTAGE (BDV) VERSUS ELECTRODE GAP FOR PULSE P1 APPLIED AT $\dot{\mathrm{m}}=45.2 \mathrm{MG} / \mathrm{SEC}$.

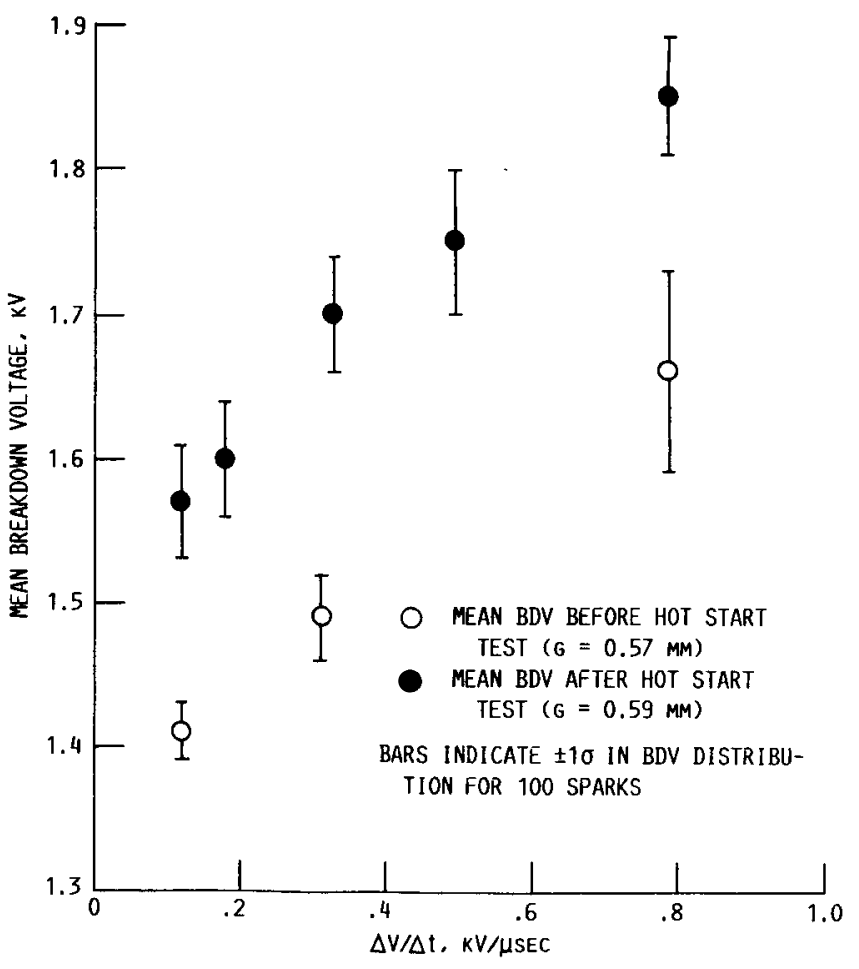

FIGURE 8. - MEAN BREAKDOWN VOLTAGE (BDV) VERSUS AVERAGE RATE OF VOLTAGE RISE, $\triangle V / \Delta t$ FOR PULSE P1 APPLIED AT $\dot{M}=45.2 \mathrm{MG} / \mathrm{SEC}$. 


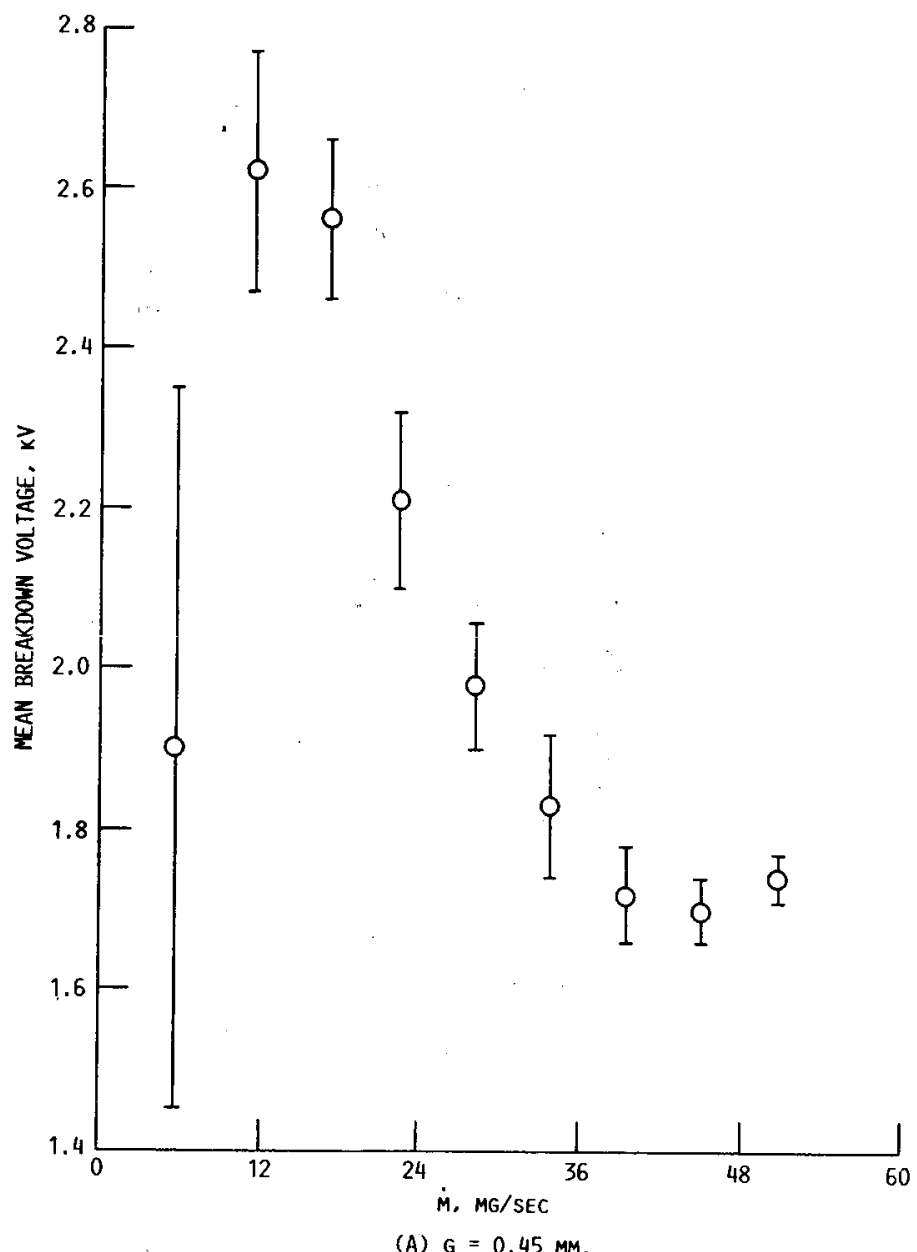

FIGURE 9. - MEAN BREAKDOWN VOLTAGE (BDV) VERSUS MASS FLOW, M OF 1:2 MOLE RATIO $\mathrm{N}_{2}: \mathrm{H}_{2}$ GAS MIXTURE FOR PULSE P1 FOR VARIOUS GAP SETTINGS, G. BARS REPRESENT \pm 10 IN BDV DISTRIBUTION FOR 100 SPARKS. 


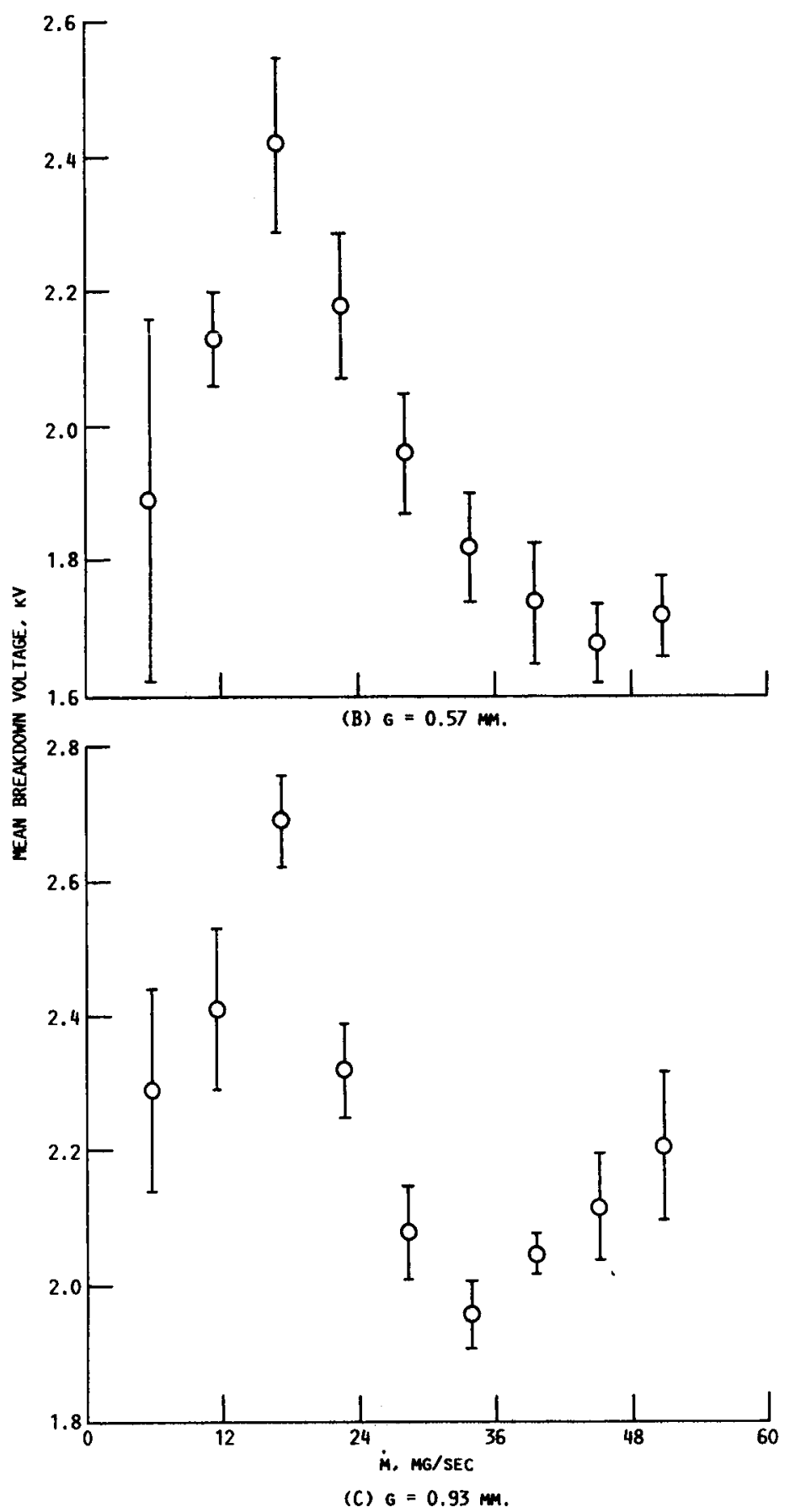

FIGURE 9. - CONCLUDED. 


\section{ORIGNAL PACE IS \\ OF POOR QUALITY}

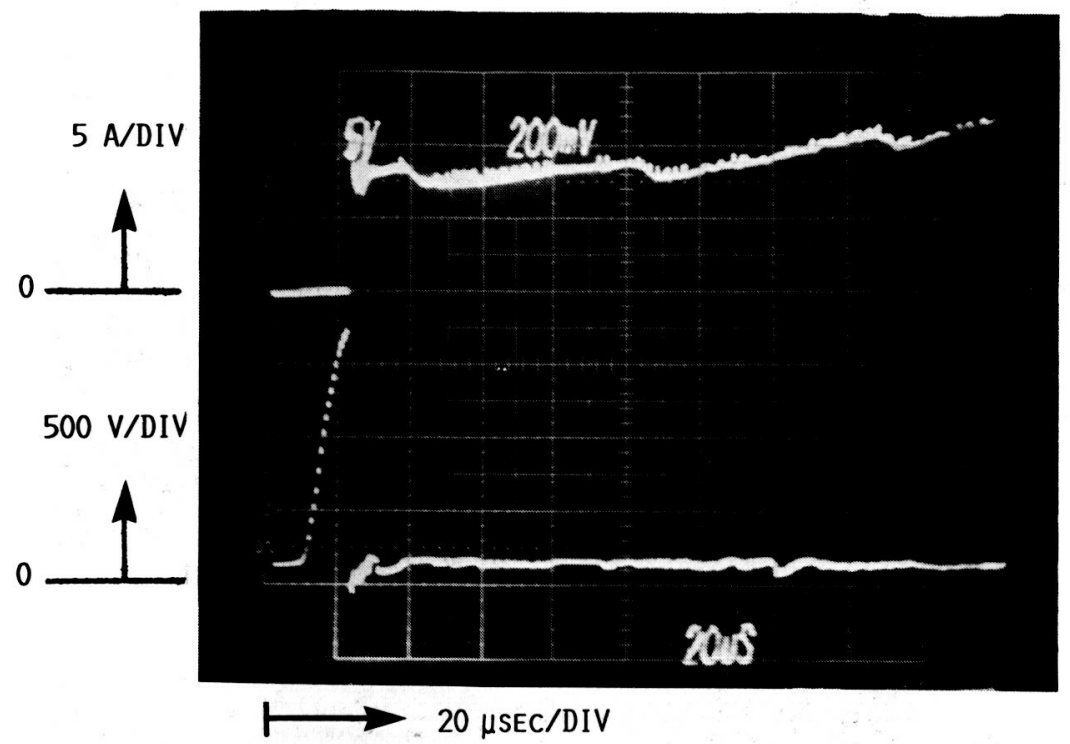

(A) SUCCESSFUL IGNITION.

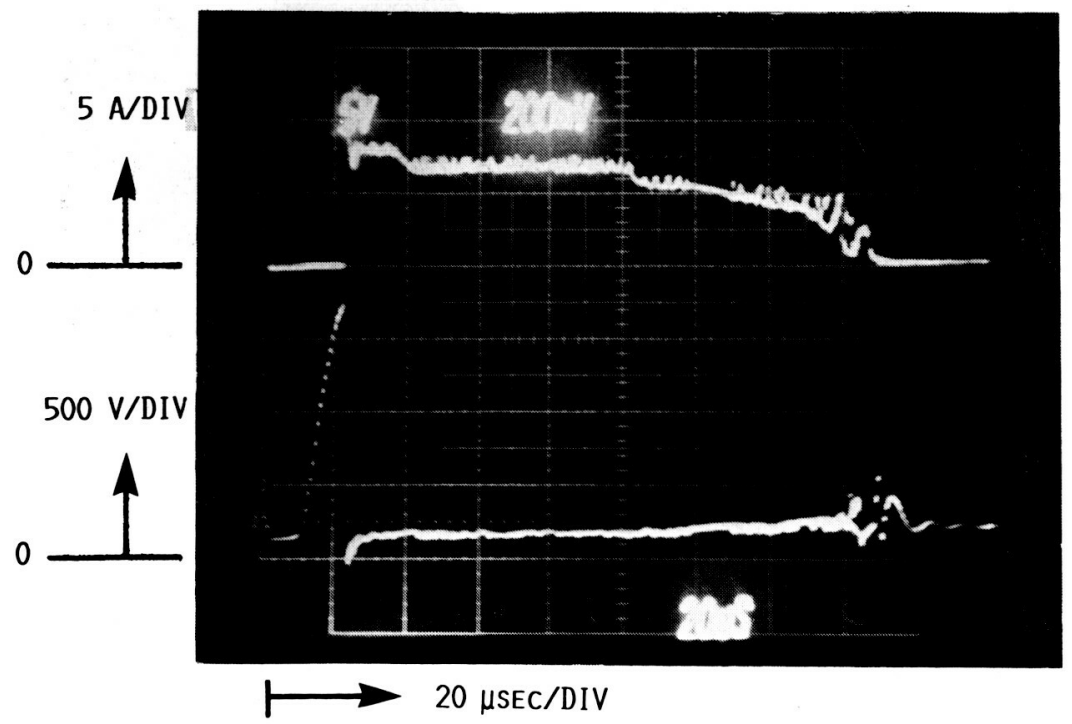

(B) UNSUCCESSFUL IGNITION.

FIGURE 10. - OSCILLOSCOPE TRACES OF THE BREAKDOWN VOLTAGES (LOWER TRACES) AND CURRENTS (UPPER TRACES) FOR ATTEMPTED HOT STARTS WITH PULSE P6 APPLIED AT $G=0.59 \mathrm{MM}$ AND $\dot{M}=45.2 \mathrm{MG} / \mathrm{SEC}$. 


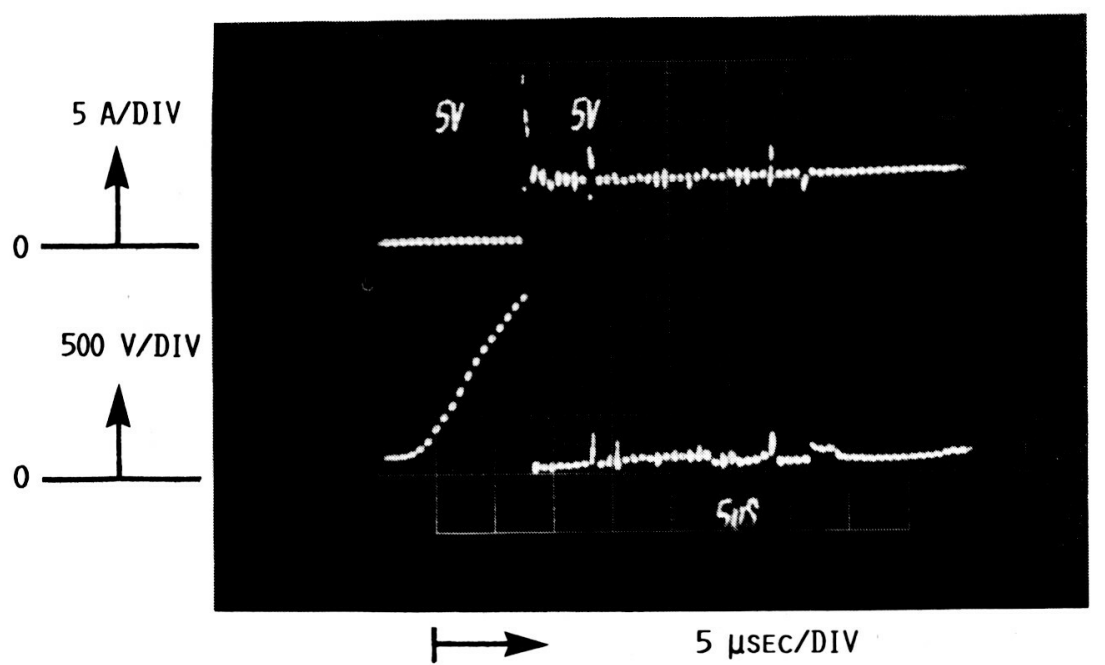

(A) SUCCESSFUL IGNITION.

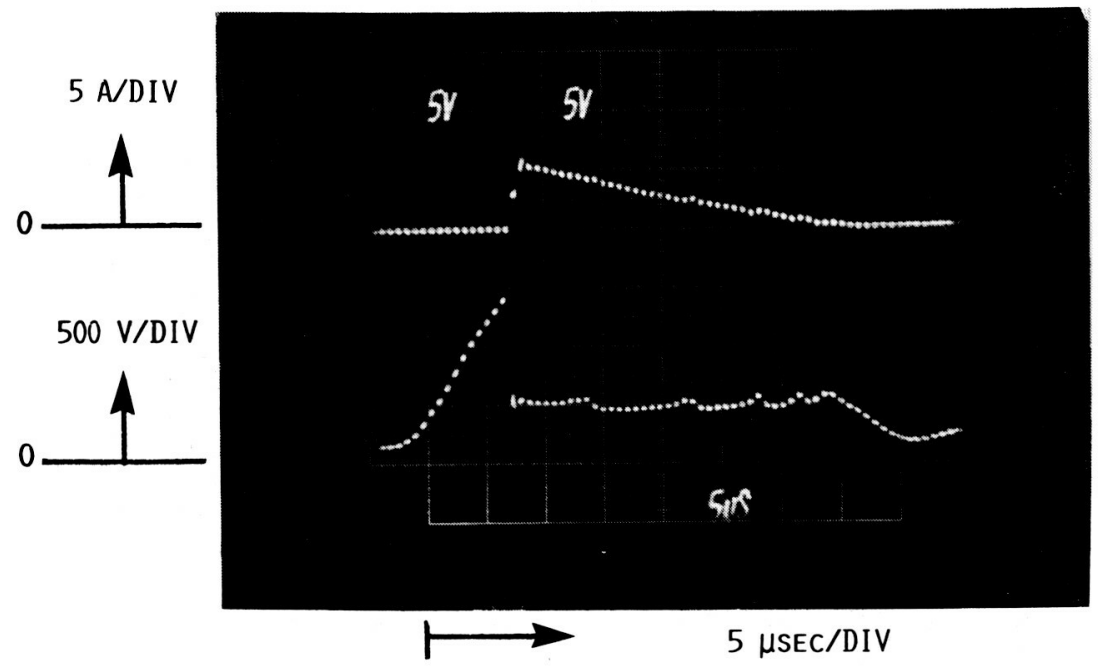

(B) UNSUCCESSFUL IGNITION.

FIGURE 11. - OSCILLOSCOPE TRACES OF BREAKDOWN VOLTAGES (LOWER TRACES) AND CURRENTS (UPPER TRACES) FOR ATTEMPTED HOT STARTS WITH PULSE P6 APPLIED AT $G=0.57 \mathrm{MM}$ AND $\dot{M}=45.2 \mathrm{MG} / \mathrm{SEC}$. 


\section{ORIGINAL PAGE IS}

OF POOR QUALITY

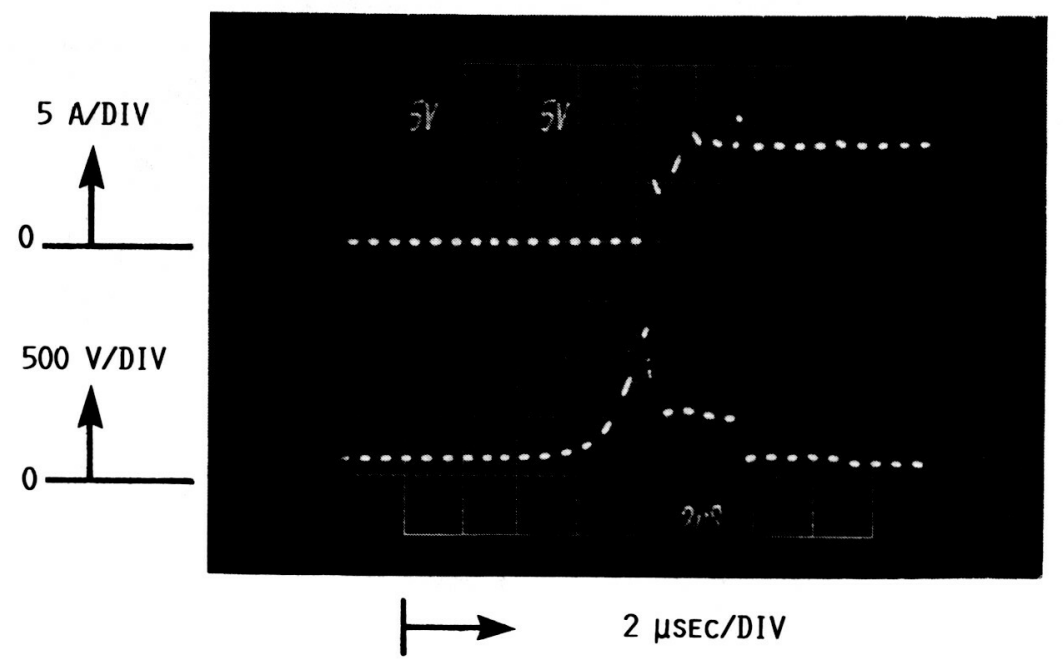

FIGURE 12. - OSCILLOSCOPE TRACE OF BREAKDOWN VOLTAGE (LOWER TRACE) AND CURRENT (UPPER TRACE) FOR A HOT START SHOWING SUCCESSFUL "STEP" IGNITION. PULSE P1 WAS APPLIED AT $G=0.57 \mathrm{MM}$ AND $\dot{M}=33.6 \mathrm{MG} / \mathrm{SEC}$. 

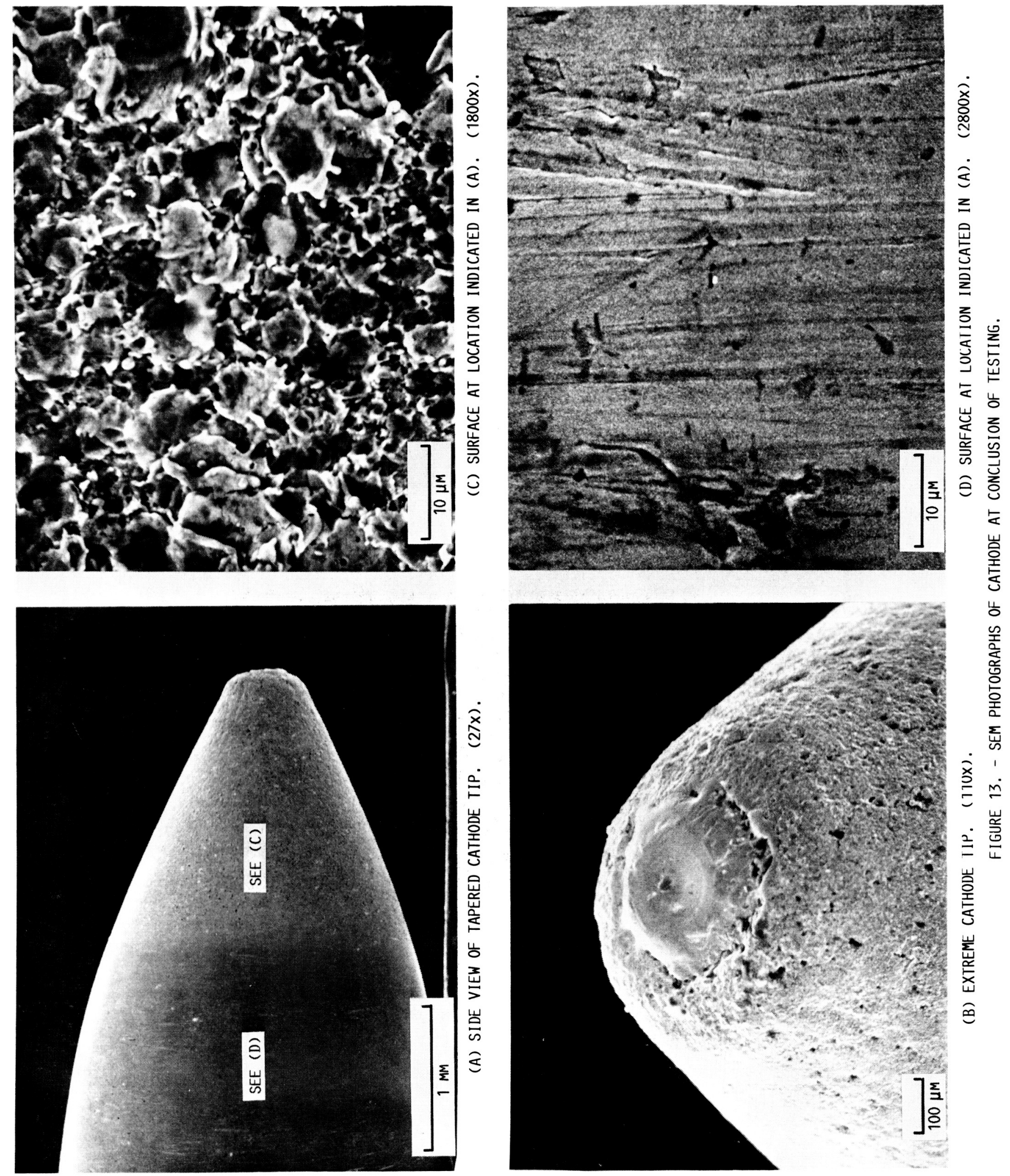


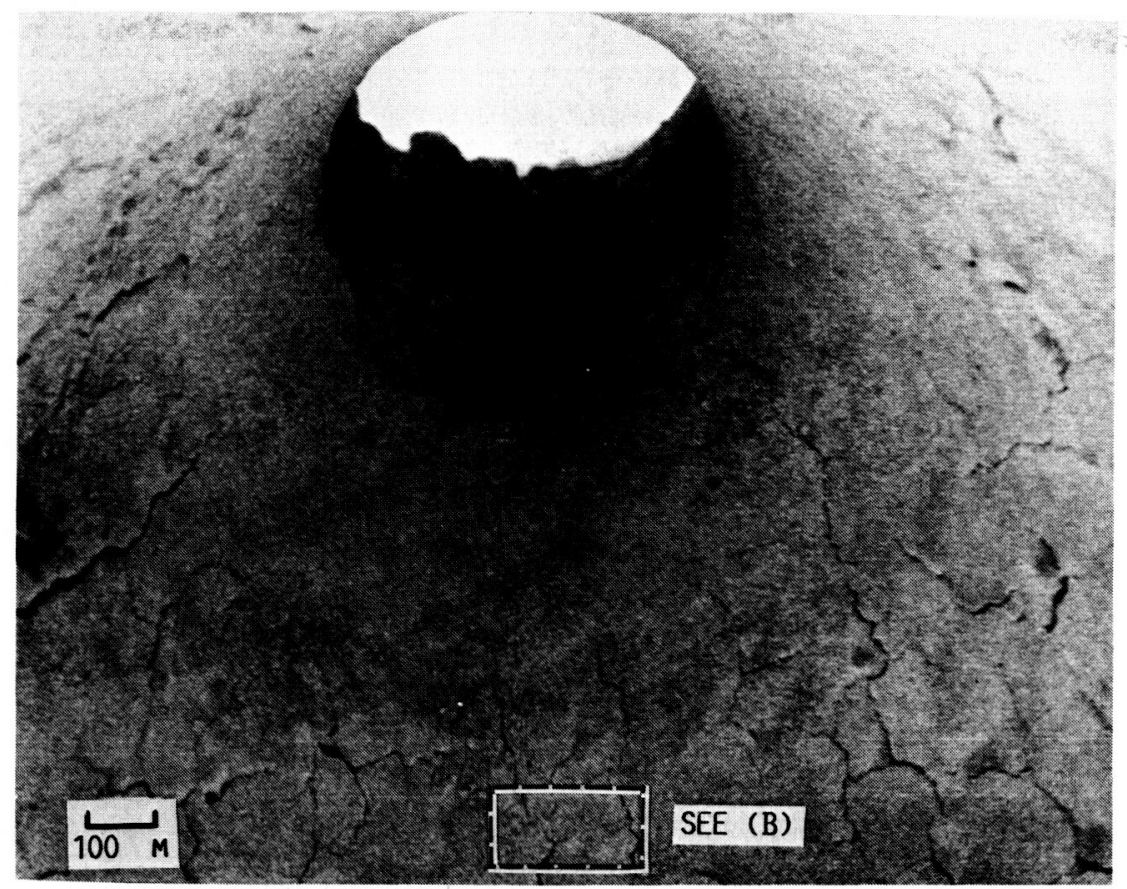

(A) ANODE CHAMBER WALL AND CONSTRICTOR. (70x).

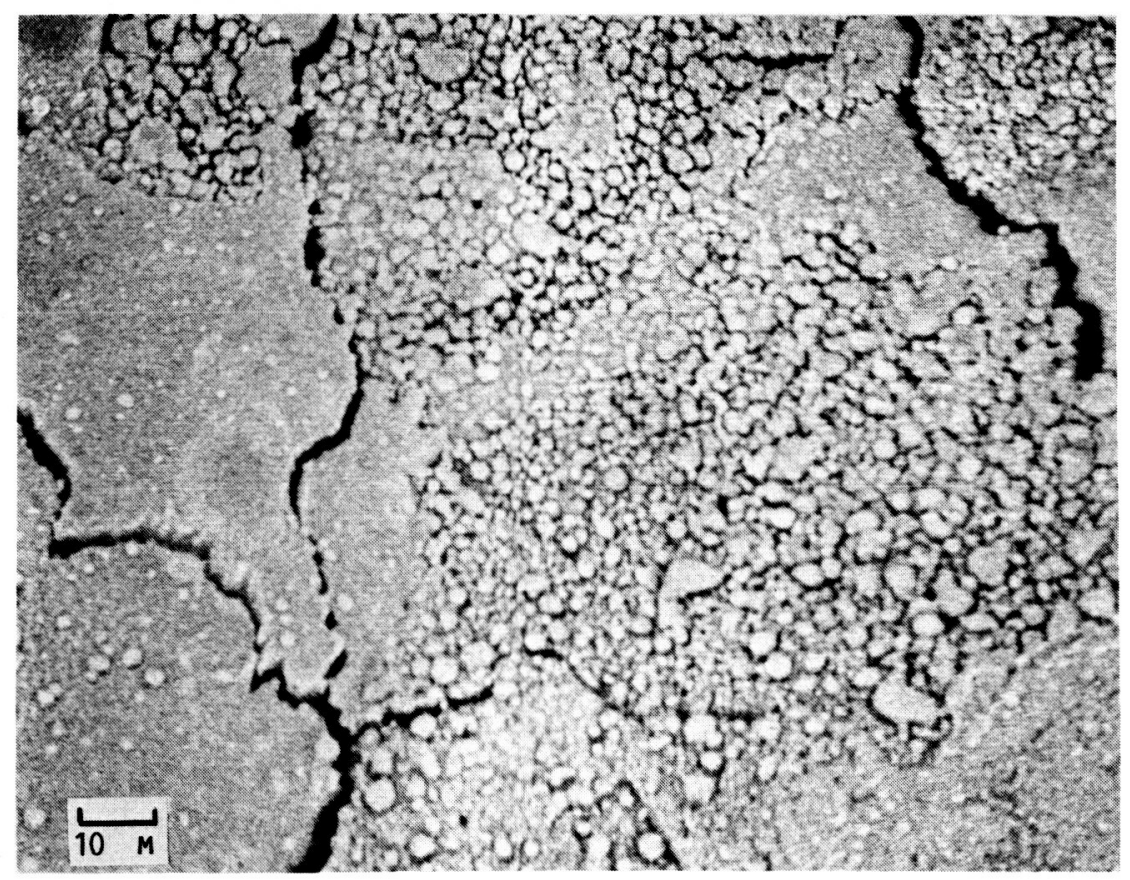

(B) SURFACE AT LOCATION SHOWN IN (A). (800x).

FIGURE 14. - SEM PHOTOGRAPHS OF CHAMBER SIDE OF ANODE AT CONCLUSION OF TESTING. 


\section{ORIGINAL PRGE IS \\ OF POOR QUALTTY}

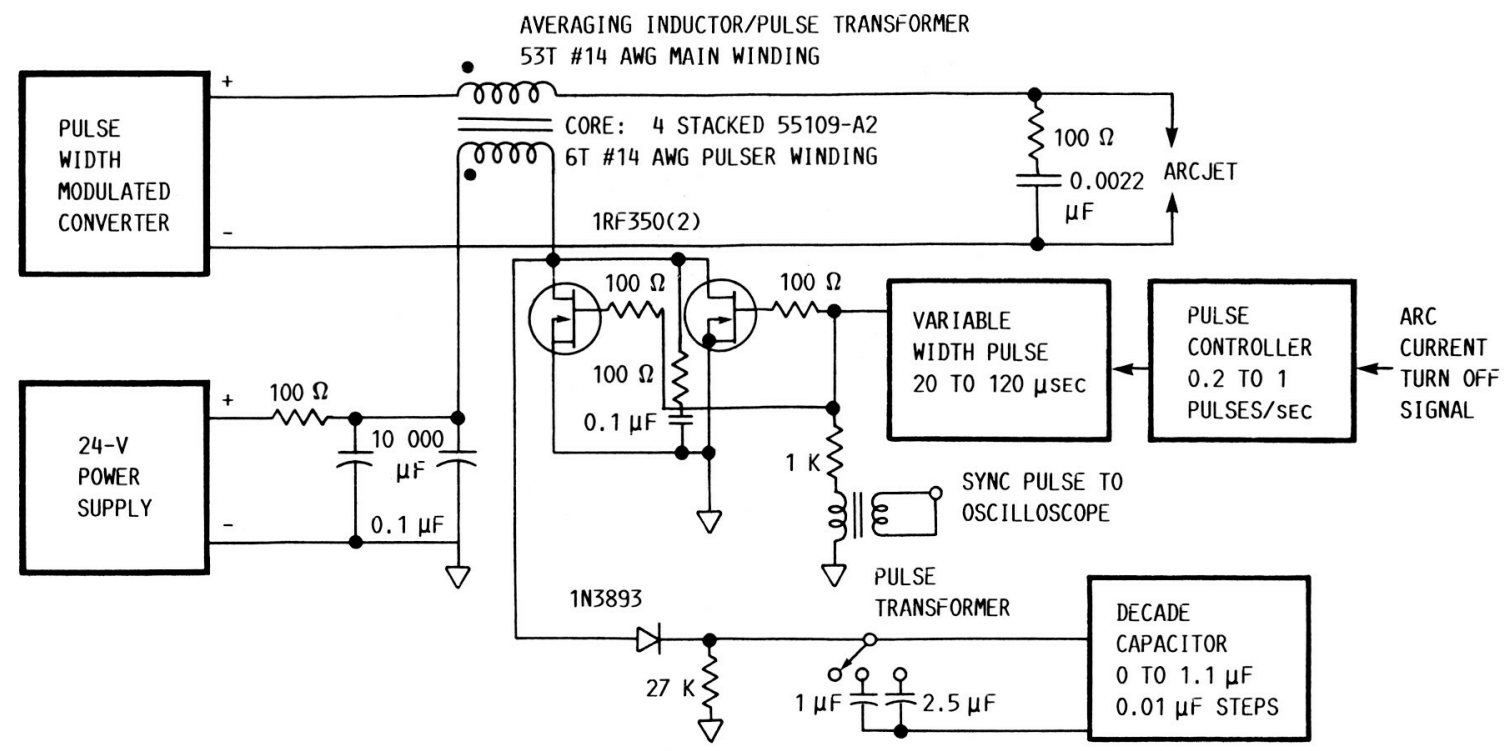

FIGURE A1. - SCHEMATIC DIAGRAM OF LABORATORY PULSER.

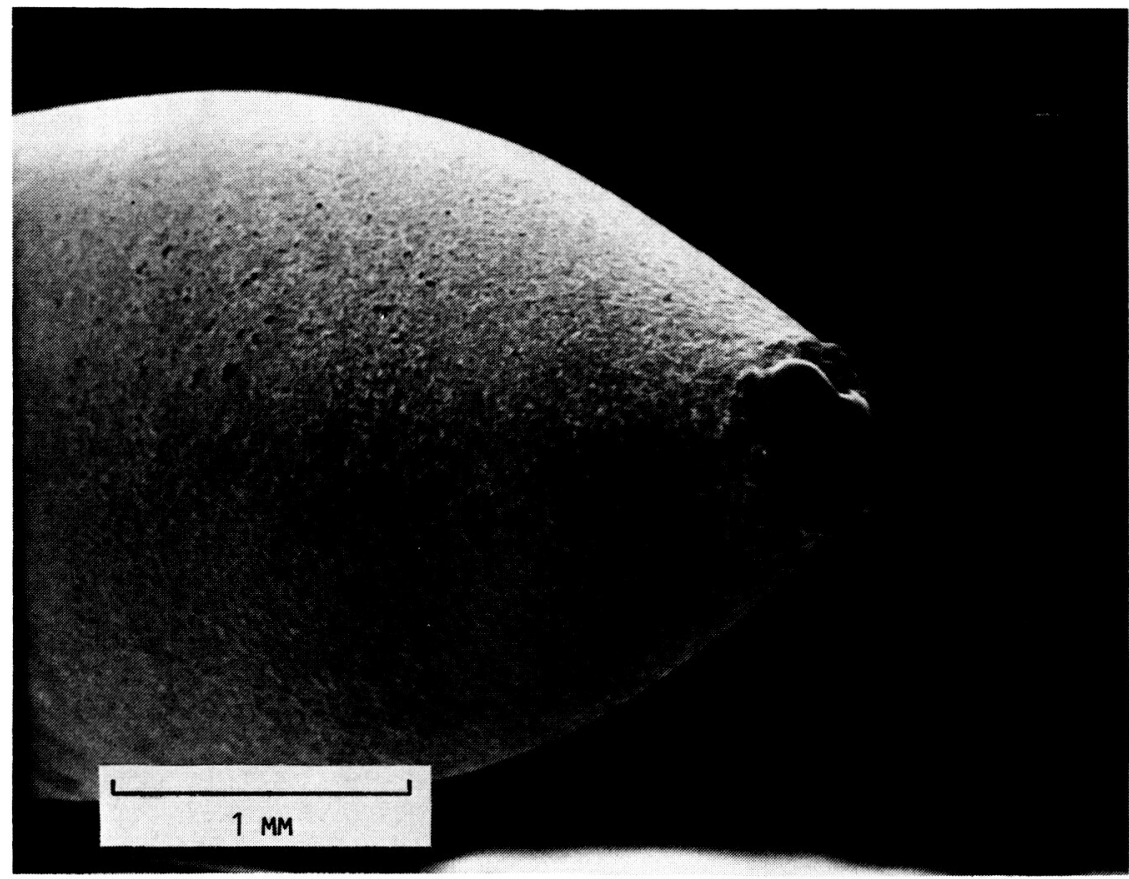

FIGURE B1. - SEM PHOTOGRAPH OF CATHODE USED IN 11600 CYCLE TEST AT CONCLUSION OF TEST $(29 x)$. 


\section{ORIGINAL PAGE IS OF POOR QUALTY}

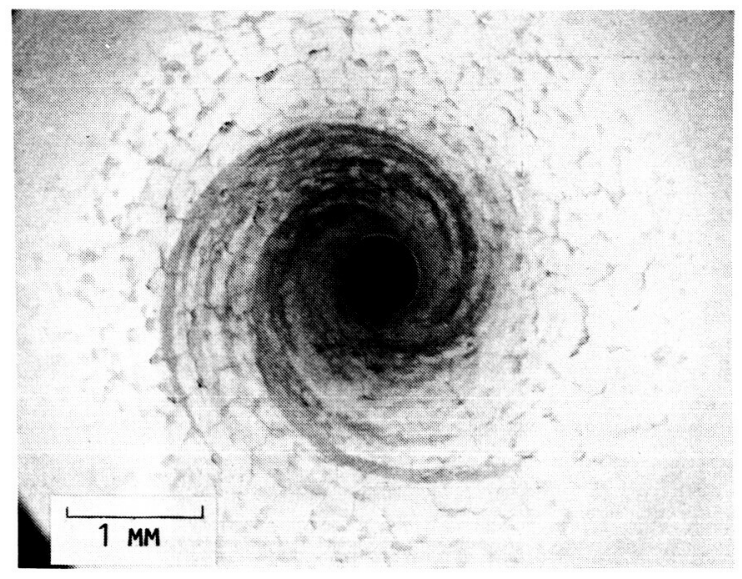

(A) CHAMBER BEFORE TEST (21x).

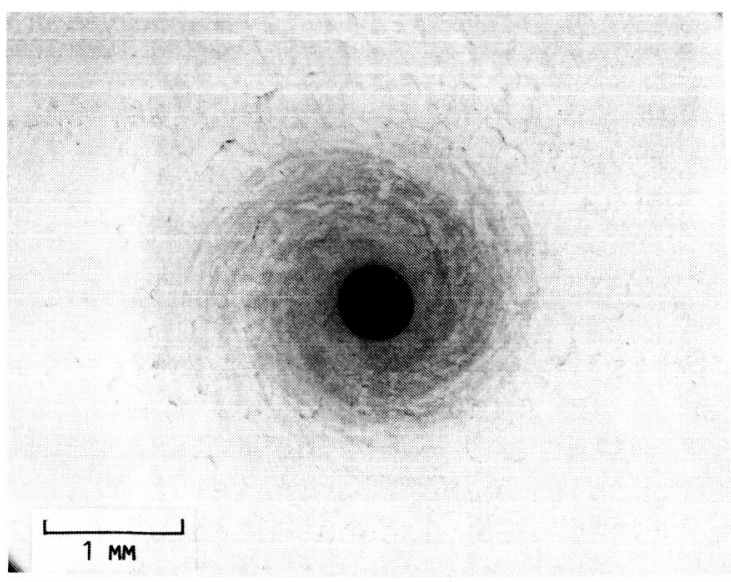

(C) CHAMBER AFTER TEST (21x).

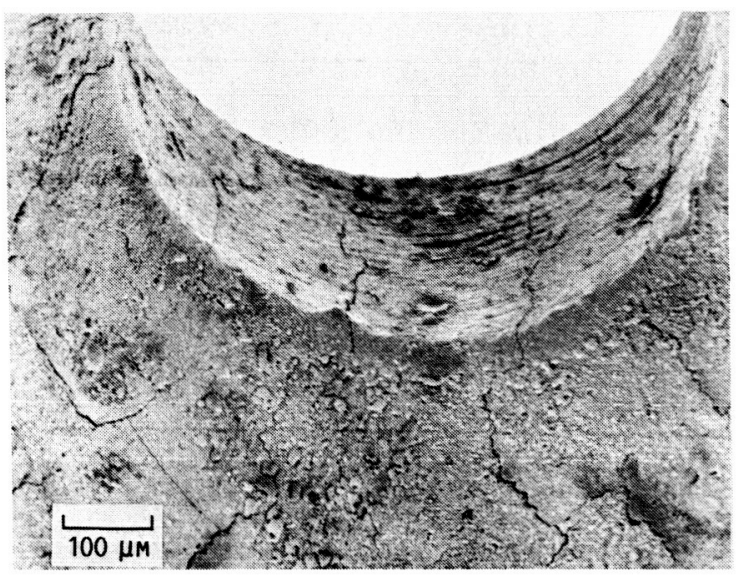

(B) ENTRANCE TO CONSTRICTOR BEFORE TEST (140x).

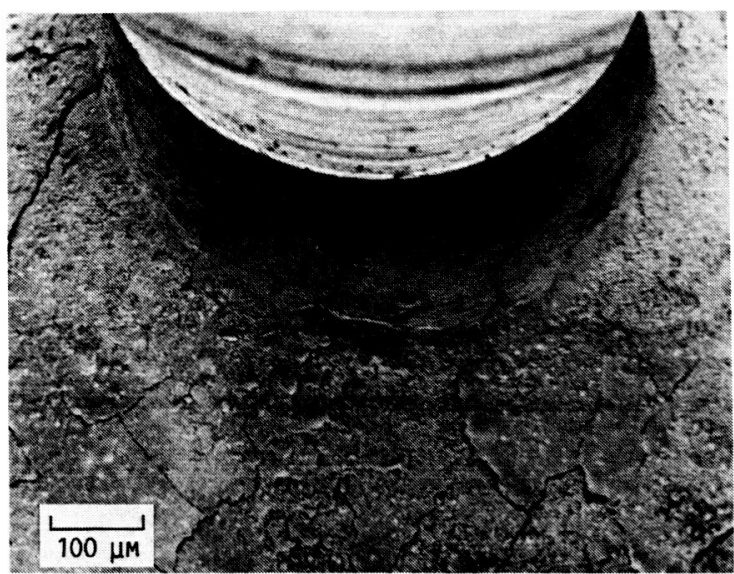

(D) ENTRANCE TO CONSTRICTOR AFTER TEST (130x).

FIgURE B2. - SEM PHOTOGRAPHS OF CHAMBER SIDE OF ANODE USED IN 11600 CYCLE TEST. 


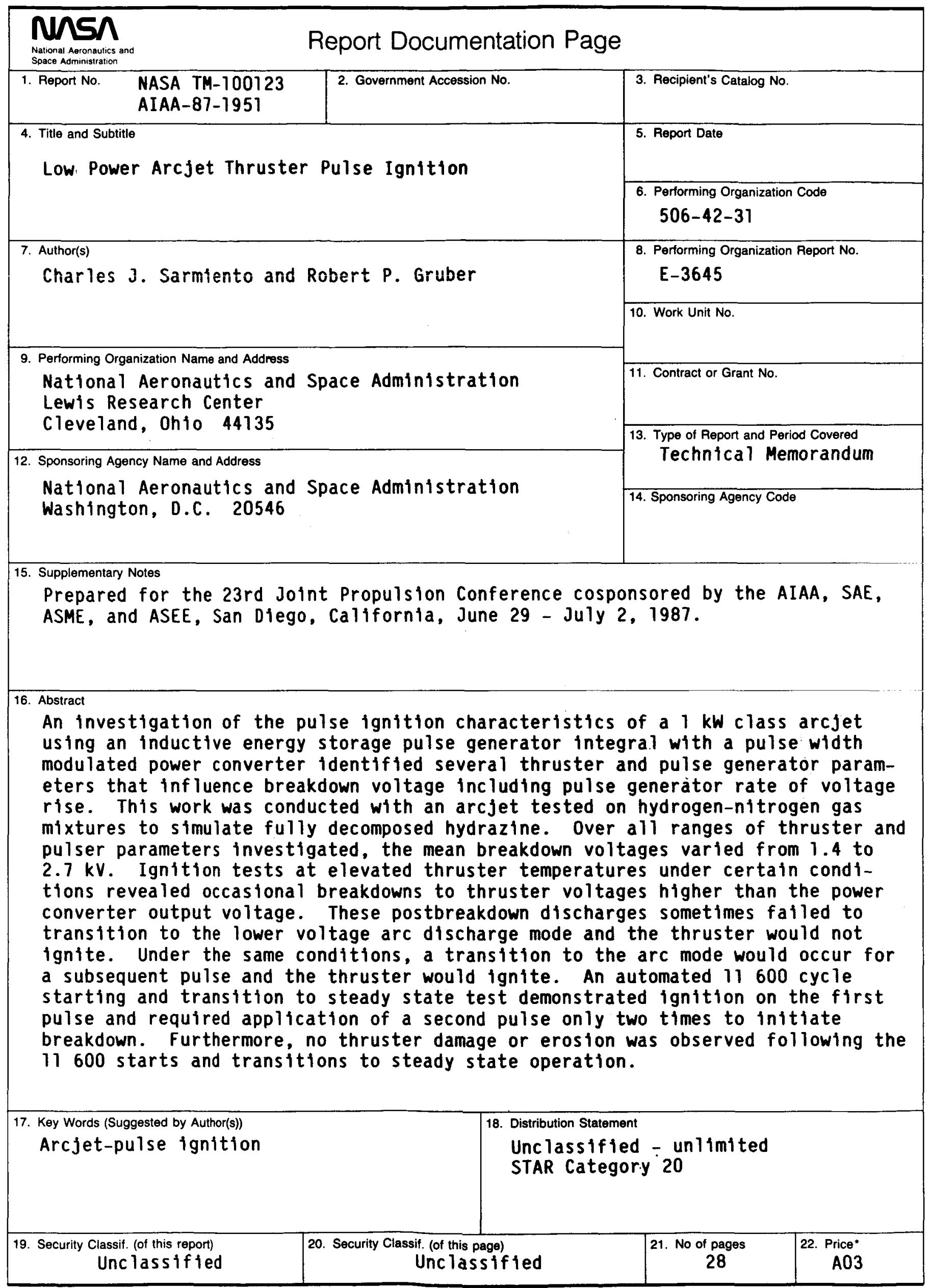

